\title{
Increase of long-chain branching by thermo-oxidative treatment of LDPE: Chromatographic, spectroscopic, and rheological evidence
}

\author{
Víctor Hugo Rolón-Garrido ${ }^{\text {a) }}$ \\ Chair of Polymer Engineering / Polymer Physics, Berlin Institute of Technology \\ (TU Berlin), Fasanenstrasse 90, D-10623 Berlin, Germany
}

\begin{abstract}
Martin Zatloukal
Polymer Centre, Faculty of Technology, Tomas Bata University in Zlin, TGM 275, Zlin 76272, Czech Republic and Centre of Polymer Systems, University Institute, Tomas Bata University in Zlin, Nad Ovcirnou 3685, 76001 Zlin, Czech Republic
\end{abstract}

\author{
Manfred H. Wagner \\ Chair of Polymer Engineering / Polymer Physics, Berlin Institute of Technology \\ (TU Berlin), Fasanenstrasse 90, D-10623 Berlin, Germany
}

(Received 20 December 2011; final revision received 26 September 2012; published 7 November 2012)

\begin{abstract}
Synopsis
Low-density polyethylene was thermo-oxidatively degraded at $170{ }^{\circ} \mathrm{C}$, i.e., degraded in the presence of air, by a one thermal cycle (1C) treatment during times between 30 and $90 \mathrm{~min}$, and by a two thermal cycles (2C) treatment, i.e., after storage at room temperature, an already previously degraded sample was further degraded during times between 15 and 45 min. Characterization methods include gel permeation chromatography (GPC), Fourier transform infrared (FTIR) spectroscopy, as well as linear and nonlinear rheology. A reduction of molar mass was detected for all degraded samples by GPC, as well as an increase of the high molar mass fraction of the 1C sample degraded for the longest time. Intrinsic viscosity measurements indicate also a reduction of molar mass with increasing degradation times for both $1 \mathrm{C}$ and $2 \mathrm{C}$ samples. Thermo-oxidation is confirmed for $1 \mathrm{C}$ and $2 \mathrm{C}$ samples by analyzing specific indices in FTIR. Linear viscoelasticity seems to be in general only marginally affected by thermo-oxidative exposure, while the enhanced strain-hardening effect observed in uniaxial extension experiments presents a clear evidence for an increased long-chain branching (LCB) content in both $1 \mathrm{C}$ and 2C samples. Elongational viscosity data were analyzed by the molecular stress function (MSF) model as well as the Wagner-I model, and for both models, quantitative description of the experimental data for all samples was achieved by fit of only one nonlinear model parameter. Time-deformation separability was confirmed for all samples degraded, 1C as well as 2C, for cumulative degradation times of up to $90 \mathrm{~min}$. The characterization by GPC was confronted with the characterization obtained from nonlinear rheology. It can be stated that elongational rheology is a powerful method to detect structural
\end{abstract}

\footnotetext{
${ }^{\text {a) }}$ Author to whom correspondence should be addressed; electronic mail: victor.h.rolongarrido@tu-berlin.de
} 
changes due to thermo-oxidative degradation, especially the formation of enhanced LCB. It has the further advantage that experimental data can be quantified by a single nonlinear model parameter of constitutive equations like the MSF or the Wagner-I model. (C) 2013 The Society of Rheology. [http://dx.doi.org/10.1122/1.4763567]

\section{INTRODUCTION}

The term "thermo-oxidative degradation" is usually associated with the undesired change of properties of a material submitted to an external source of heat and in presence of oxygen. Polyethylene is one of the important commodity polymers in the market, and it is therefore not surprising that many efforts were focused on understanding the thermooxidative degradation of polyethylene, since degradation is of crucial relevance for processing [Hinsken et al. (1991); Johnston and Morrison (1996); Epacher et al. (2000)], for performance under service conditions [Gijsman (2008)], and for recycling [Hakkarainen and Albertsson (2004); Roy et al. (2011)]. Chain scission and cross-linking [Arnett and Stacy (1966); Meltzer and Supnik (1964)] as well as long-chain branching (LCB) [Holmström and Sörvik (1974)] have been identified as the main structural modifications in polyethylene as a consequence of thermal degradation. Details on the chemical reactions occurring during thermo-oxidative degradation can be found, e.g., in Holmström and Sörvik (1978), Tüdos and Iring (1988), and Gugumus (2002).

Methods to quantify the change of properties of polyethylene due to thermal degradation include measurements of activation energies by thermogravimetry [Cho et al. (1998); Peterson et al. (2001)] and comparison with results obtained by chemiluminescence [Rychly et al. (2011)], measurements of elongation at break by mechanical tests in solid state [Budrugeac and Segal (1998)], measurements of reaction and free activation enthalpies by pyrolysis [Koc et al. (2009)], and determination of chemical group variations by spectroscopic methods like fluorescence [Konar and Ghosh (1990)] or Fourier transform infrared (FTIR) data [Cho et al. (1998); Peterson et al. (2001)]. In fact, models have been developed describing thermal degradation as obtained by FTIR spectroscopy [Gugumus (1996b); Salvalaggio et al. (2006)]. In this context, differential scanning calorimetry (DSC) has been applied to obtain the heat of fusion and the melting points [Holmström and Sörvik (1978); Volke-Sepúlveda et al. (1999)], and gel permeation chromatography (GPC) to identify the variations in structure and molecular weight distribution (MWD) [Holmström and Sörvik (1978); Iring et al. (1980); Kumar et al. (2002)].

Rheology is well known to detect with high sensitivity variations of the polymer structure [Gahleitner (2001); Münstedt (2011)], although as far as the influence of thermo-oxidative degradation is concerned, the studies have been focused mainly on the linear-viscoelastic regime both experimentally [Mariani et al. (2002); Shangguan et al. (2010)] and theoretically [Drozdov (2007)]. In the context of the present contribution, low-density polyethylene (LDPE) was treated thermally and thermo-oxidatively, and it was reported recently that strain hardening in uniaxial elongation is the stronger, the longer the oxidative time is, which was explained as the effect of an enhanced LCB content induced by thermo-oxidative degradation [Rolón-Garrido et al. (2011a)]. For samples thermally degraded in the absence of oxygen, this effect was not so significant. The experimental data were analyzed in the framework of the molecular stress function (MSF) model for polydisperse branched polymer melts. To the best of our knowledge, there exists only one earlier report on enhanced strain hardening due to formation of branched molecules by thermo-mechanical degradation [La Mantia et al. (1989)], but this concerns high density polyethylene.

The MSF model is a single tube segment integral constitutive equation, with the main feature of including the stretch as a relative quantity inside the history integral. Considering the interchain tube pressure effect in the evolution equation for the stretch, elongational rheology 
of monodisperse linear polymer melts could be modeled successfully [Rolón-Garrido et al. (2006)]. Further development of the MSF model showed that nonlinear viscoelastic experiments in shear and elongation of linear mono and bidisperse polymer systems can be described by a tube diameter relaxation time related to the Rouse stretch relaxation time. For bidisperse polymers, the role of dynamic dilution was elucidated [Wagner and RolónGarrido (2010); Wagner (2011)]. Model branched structures have also been analyzed by the MSF approach like H-polymers in uniaxial elongation [Wagner and Rolón-Garrido (2008)] and comb polymers in medium amplitude oscillatory shear flow [Wagner et al. (2011)].

In the case of polydisperse branched polymer melts, the original MSF model [Wagner et al. (2001)] has the advantage that the nonlinear parameters have a specific physical meaning associated with the structure of the polymer [Wagner et al. (2001); Wagner et al. (2004); Rolón-Garrido and Wagner (2007); Abbasi et al. (2012)]. This version of the MSF model has been applied to describe quantitatively and simultaneously nonlinear shear and elongational flows of LDPE with a minimum number of parameters [RolónGarrido et al. (2009)]. It has been also used in numerical simulations of planar contraction flow [Olley and Wagner (2006)], and in numerical simulations of polymer processes like compression molding [Eriksson and Rasmussen (2005)], inflation of a flat plate [Rasmussen and Bach (2005); Rasmussen and Yu (2008)], and gas displacement of polymer melts in a cylinder [Rasmussen and Eriksson (2007)].

The objective of this contribution is to present new and compelling experimental evidence that thermo-oxidative treatment induces structural modifications in LDPE by increasing the LCB content. Characterization methods include GPC, FTIR spectroscopy, as well as rheometry. Elongational viscosity data are analyzed in the framework of the MSF and Wagner-I models.

\section{EXPERIMENTS}

\section{A. Sample preparation}

LDPE Lupolen 1840D, previously characterized rheologically by Rasmussen et al. (2005), Resch (2010), and Rolón-Garrido et al. (2011b), was employed as test material. The polymer is supplied as granules and was used as received. The LDPE granules were homogenized first in a single screw extruder at $160^{\circ} \mathrm{C}$, and afterwards the polymer melts were pressed to plates of roughly $200 \mathrm{~mm}$ in diameter and approximately $0.7 \mathrm{~mm}$ in thickness in a hot press and immediately cooled down. The extrusion conditions were carefully kept low enough to avoid degradation as far as possible. The sample thus obtained is denoted in the following as reference (nondegraded) sample LDPE-T0.

Later, these samples were put in an oven at $170{ }^{\circ} \mathrm{C}$ under air reflux during exposure times from 30 to $90 \mathrm{~min}$ with $15 \mathrm{~min}$ increments in between. In this way, the samples denoted in the following as "thermo-oxidized in one thermal cycle" (1C) were prepared. The notation of the samples is based on the treatment time. Thus, LDPE-O60 means that the sample was oxidatively degraded during $60 \mathrm{~min}$. For comparative purposes, sample preparation was kept similar to the one applied earlier to LDPE 3020D [Rolón-Garrido et al. (2011a)].

To determine the stability of the thermo-oxidative degradation, one sample LDPE O45 was kept for 3 months at room temperature and at atmospheric conditions. Afterwards, the plate was cut into 4 pieces. One piece, denoted as LDPE O $45+0$, was characterized as it was, while the other pieces were further degraded for 15, 30, and $45 \mathrm{~min}$, respectively. The samples thus produced by two cycles of thermo-oxidative degradation (2C) are denoted as LDPE O45+15, LDPE O45+30, and LDPE O45+45.

A crucial issue needing consideration is the homogeneity of the degraded films. In polyethylene at atmospheric pressure, degradation is dominated by oxidation [Colin et al. 
(2004)]. At elevated temperatures, the consumption rate of oxygen in nonstabilized polyethylene is larger than the resupply of oxygen by diffusion, leading to diffusion-limited oxidation effects [Gillen et al. (1995)] which may be described by first-order kinetics [Audouin et al. (1994)]. On the other hand, the commercial polyethylene investigated here contains antioxidant. Also, the characteristic diffusion time $t_{\mathrm{D}}$ [Crank and Park (1968)],

$$
t_{\mathrm{D}}=\frac{d^{2}}{6 D}
$$

with the sample thickness $d=0.7 \mathrm{~mm}$ and the diffusion coefficient $D=9 \times 10^{-9} \mathrm{~m}^{2} / \mathrm{s}$ of oxygen in polyethylene at $170^{\circ} \mathrm{C}$ [van Krevelen and te Nijenhuis (2009)] turns out to be $t_{\mathrm{D}}=9 \mathrm{~s}$. Comparing this to oxidation times of $15 \mathrm{~min}$ and longer, we may conclude that the films are homogeneously degraded.

\section{B. Characterization methods}

MWD was measured by a high-temperature gel permeation chromatograph (PL-GPC 220, Varian Inc.) equipped with a refractive index and a viscosity detectors. The measurements were performed at $160^{\circ} \mathrm{C}$ using 1,2,4-trichlorbenzene as solvent and $0.025 \mathrm{wt}$. $\%$ of Santonox R as antioxidant to prevent further degradation during the measurement. To verify reproducibility, two measurements were performed for each sample.

A Nicolet 380 (Thermo Electron Corporation) was employed to obtain FTIR spectra in the range of $400-4000 \mathrm{~cm}^{-1}$ with 40 consecutive scans at a resolution of $0.96 \mathrm{~cm}^{-1}$. The spectra were recorded in reflective mode of the sample plates used for the rheological characterization. In evaluating the spectra, special attention was paid to the absorption peaks at $1715 \mathrm{~cm}^{-1}$ associated with ketone carbonyl, $1640 \mathrm{~cm}^{-1}$ related to C-C double bonds, and $1465 \mathrm{~cm}^{-1}$ related to methylene groups. The carbonyl index $(\lambda=1715 / 1465)$ and the double bond index $(\lambda=1640 / 1465)$ are a measure of the concentration of carbonyl and double bonds, respectively [Albertsson et al. (1987)]. The advantage of the normalization of the adsorption peaks with an invariant absorbance band of the polymer is the compensation for differences in the thickness of the samples [Albertsson et al. (1987)]. The carboxylic groups are related to the amount of oxygen consumed by the polyethylene in the oxidation [Fodor et al. (1991)], therefore playing a crucial role in the study of thermo-oxidative degradation of polyethylene [Iring et al. (1980); Gugumus (1996a); Volke-Sepúlveda et al. (1999)]. The changes in the double bond index have been interpreted as a possible result of splitting of hydroperoxyde and formation of carboxylic acid [Albertsson et al. (1987)], and consequently was also used together with the carbonyl index in the study of thermo-oxidized LDPE [Volke-Sepúlveda et al. (1999)].

Other bands analyzed are those used to evaluate crystallinity (peaks at 720, 730, 1474, and $1464 \mathrm{~cm}^{-1}$ ), and attention was also paid to those related to chain branching (bands between 909 and $1653 \mathrm{~cm}^{-1}$ ) [Pages et al. (1996); Carrasco et al. (2001)]. It should be mentioned that the spectra measured by FTIR were taken from the side of the film, which was not in contact with oxidative atmosphere, indicating that the structural modification has occurred throughout the whole sample.

Additionally, DSC and mechanical tests in solid state were performed without any significant differences in the quantities measured between degraded and reference samples. Therefore, these results are not presented here.

Rheological measurements were carried out by use of a Physica MCR301 rheometer equipped with a CTD450 convection oven (Anton Paar). In oscillatory shear flow, plateplate geometry with a diameter of $25 \mathrm{~mm}$ and a gap of roughly $0.75 \mathrm{~mm}$ was used to 
TABLE I. Relaxation spectrum of LDPE-T0 obtained from the measurement at $170{ }^{\circ} \mathrm{C}$ and for LDPE-O90 obtained through the Levenberg-Marquardt technique based on the experimental data of the start-up of elongational flow.

\begin{tabular}{|c|c|c|c|}
\hline \multicolumn{2}{|c|}{ LDPE-T0 } & \multicolumn{2}{|c|}{ LDPE-O90 } \\
\hline \multicolumn{2}{|c|}{$\eta_{0}=2.133 \times 10^{5} \mathrm{~Pa} \cdot \mathrm{s}$} & \multicolumn{2}{|c|}{$\eta_{0}=2.006 \times 10^{6} \mathrm{~Pa} \cdot \mathrm{s}$} \\
\hline$g_{i}(\mathrm{~Pa})$ & $\lambda_{i}(\mathrm{~s})$ & $g_{i}(\mathrm{~Pa})$ & $\lambda_{i}(\mathrm{~s})$ \\
\hline $1.819 \times 10^{5}$ & $7.922 \times 10^{-4}$ & $5.614 \times 10^{4}$ & $4.295 \times 10^{-2}$ \\
\hline $6.192 \times 10^{4}$ & $5.241 \times 10^{-3}$ & $1.942 \times 10^{3}$ & $1.977 \times 10^{0}$ \\
\hline $3.968 \times 10^{4}$ & $2.446 \times 10^{-2}$ & $1.805 \times 10^{4}$ & $0.698 \times 10^{0}$ \\
\hline $2.437 \times 10^{4}$ & $1.132 \times 10^{-1}$ & $6.451 \times 10^{3}$ & $2.821 \times 10^{2}$ \\
\hline $1.438 \times 10^{4}$ & $5.190 \times 10^{-1}$ & $2.328 \times 10^{3}$ & $1.383 \times 10^{1}$ \\
\hline $7.518 \times 10^{3}$ & $2.455 \times 10^{0}$ & $1.564 \times 10^{3}$ & $8.457 \times 10^{1}$ \\
\hline $3.665 \times 10^{3}$ & $1.170 \times 10^{1}$ & $8.682 \times 10^{2}$ & $1.106 \times 10^{0}$ \\
\hline $1.347 \times 10^{3}$ & $1.041 \times 10^{2}$ & $1.127 \times 10^{3}$ & $1.668 \times 10^{1}$ \\
\hline
\end{tabular}

characterize the reference sample under nitrogen atmosphere to avoid degradation. From frequency sweep test performed to LDPE-T0 in the linear-viscoelastic region at $170{ }^{\circ} \mathrm{C}$, a discrete relaxation spectrum was calculated using the IRIS software. ${ }^{1}$ Partial relaxation moduli $g_{i}$ and relaxation times $\lambda_{i}$ as well as the zero-shear viscosity $\eta_{0}$ are presented in Table I. The experimentally obtained storage $G^{\prime}$ and loss $G^{\prime \prime}$ moduli as well as the fit by the relaxation spectrum are presented in Fig. 1. Due to the lack of thermal stability of the degraded samples, oscillatory shear measurements could not be performed. However, it was observed earlier that the linear-viscoelastic regime is not strongly affected by thermooxidative treatment [Rolón-Garrido et al. (2011a)], and therefore the discrete relaxation spectrum of the reference sample was also used to model the nonlinear rheology of the degraded specimens. Only in the case of LDPE O90 we found that this method was not applicable since the zero-elongation-rate viscosity $\mu_{0}(t)$ is indeed strongly affected by degradation. Thus, in this case, the relaxation spectrum was determined from the linearviscoelastic start-up curve by use of a Levenberg-Marquardt technique.

To measure the elongational viscosity, a Sentmanat Extensional Rheometer (model SER2$\mathrm{P}$ universal testing platform from Xpansion Instruments) was used, which is a dual windup extensional rheometer operating at constant elongation rate and tailored to the MCR301 rheometer [Sentmanat (2004)]. The protocol to correct the effects of thermal expansion and of prestretch for minimal sagging is described elsewhere [Rolón-Garrido et al. (2011a)].

\section{THEORY}

Attention is restricted here to constitutive equations, which obey the principle of timedeformation separability (K-BKZ separable), e.g., constitutive equations of the form

$$
\boldsymbol{\sigma}(\mathrm{t})=\int_{-\infty}^{\mathrm{t}} \stackrel{\circ}{m}\left(t-t^{\prime}\right) \boldsymbol{S}_{\mathrm{m}}\left(t, t^{\prime}\right) \mathrm{d} t^{\prime},
$$

${ }^{1}$ Winter, H. H., and M. Mours, IRIS Developments, http://rheology.tripod.com/ (2003). 


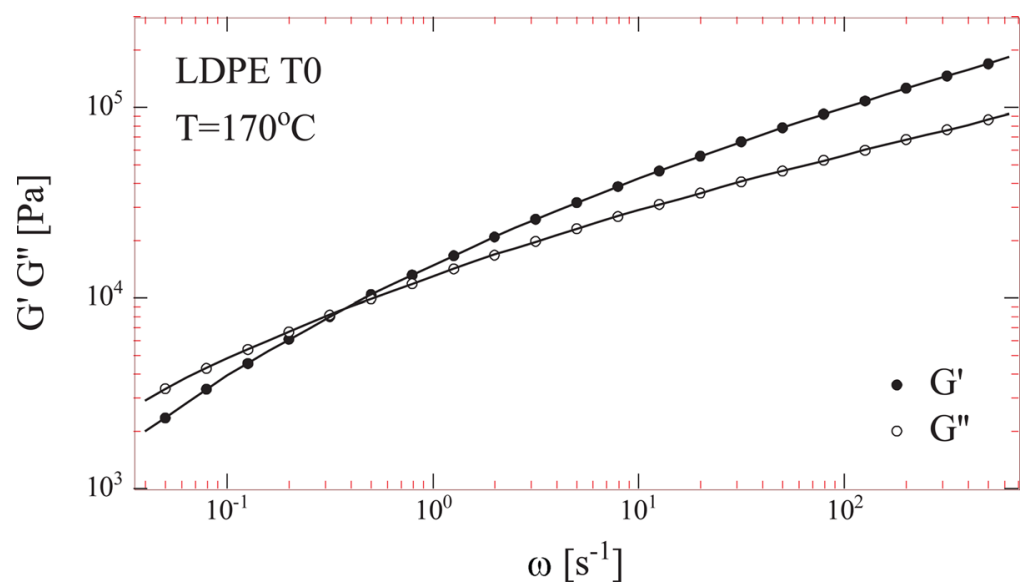

FIG. 1. Linear-viscoelastic data of LDPE T0 at $170^{\circ} \mathrm{C}$. Continuous lines indicate the fit by use of discrete relaxation spectrum of Table I.

where $\boldsymbol{\sigma}(\mathrm{t})$ is the extra stress tensor, and $\stackrel{\circ}{m}\left(t-t^{\prime}\right)$ is the linear-viscoelastic memory function related to the linear relaxation modulus $\stackrel{\circ}{G}\left(t-t^{\prime}\right)$, which will be represented in the following by a sum of the discrete relaxation modes:

$$
\stackrel{\circ}{m}\left(t-t^{\prime}\right)=\frac{d \stackrel{\circ}{G}\left(t-t^{\prime}\right)}{d t^{\prime}}=\sum_{i=1}^{N}\left(\frac{g_{i}}{\lambda_{i}}\right) e^{\frac{-\left(t-t^{\prime}\right)}{\lambda_{i}}} .
$$

$S_{\mathrm{m}}\left(t, t^{\prime}\right)$ is a general strain measure and might be considered as the deformation measure of the material [Rolón-Garrido and Wagner (2009)]. The Wagner-I model is obtained for [Wagner (1976)]

$$
\boldsymbol{S}_{\mathrm{m}}\left(t, t^{\prime}\right)=h\left(I_{1}, I_{2}\right) \boldsymbol{C}_{\mathrm{t}}^{-1}\left(t^{\prime}\right) .
$$

The Finger tensor $\boldsymbol{C}_{\mathrm{t}}^{-1}\left(\boldsymbol{t}^{\prime}\right)$ takes into account affine deformations of material lines. The damping function $h\left(I_{1}, I_{2}\right)$, which depends on the first and second invariants $I_{1}$ and $I_{2}$ of the Finger tensor, takes into account the loss of connectivity in the structure of the temporary polymer network due to deformation [Wagner (1976)]. For a review on the concept of damping functions in rheology, see Rolón-Garrido and Wagner (2009). In uniaxial extension and based on experimental data of a LDPE melt, the damping function can be expressed as [Wagner (1978)]

$$
h_{u}(\varepsilon)=[a \exp (2 \varepsilon)+(1-a) \exp (m \varepsilon)]^{-1},
$$

where $a$ and $m$ are free model parameters.

The MSF model can be recovered from Eq. (2) by

$$
S_{\mathrm{m}}\left(t, t^{\prime}\right)=f^{2} \boldsymbol{S}_{D E}^{I A}\left(t, t^{\prime}\right) .
$$

$S_{D E}^{I A}\left(t, t^{\prime}\right)$ is the strain measure representing the affine rotation of tube segments and corresponds to the so-called "independent alignment (IA)" assumption in the 
Doi-Edwards model [Doi and Edwards (1978)]. The square of the relative tension in the chain segments, $f^{2}$, is related to the strain energy stored in the polymeric system and is therefore strongly dependent on the molecular structure of the polymer. It is determined as solution of an evolution equation derived from an energy balance argument [Wagner et al. (2001)]. By considering the change of free energy for polydisperse randomly branched polymer melts, the evolution equation for $f^{2}$ was found to be in uniaxial extension [Wagner et al. (2003)]:

$$
\frac{\partial f^{2}}{\partial t}=\dot{\varepsilon} \frac{\beta f^{2}}{1+\frac{\beta-1}{f^{4}}}\left(S_{11}-S_{33}-\frac{f^{2}-1}{f_{\max }^{2}-1} \sqrt{S_{11}+\frac{1}{2} S_{33}}\right) .
$$

$\dot{\varepsilon}$ is the elongation rate in the direction of the 1-coordinate, and $S_{11}$ and $S_{33}$ are the corresponding components of the orientation tensor $S=1 / 5 S_{D E}^{I A}$ in the directions parallel and perpendicular to the stretch, respectively. For extensional deformations, the MSF model contains only two parameters, $\beta$ and $f_{\max }$. The nonlinear parameter $\beta$ is directly related to the molecular structure of the polymer and represents the ratio of the molar mass of the (branched) polymer chain to the molar mass of the backbone alone. It therefore takes the value of 1 for linear polymers [Wagner et al. (2003)]. According to the model, the side chains are compressed due to deformation [Wagner et al. (2003); Wagner et al. (2004)]. This hypothesis influences the prefactor of Eq. (7). However, no significant difference was found by assuming that the side chains are rather oriented, but not stretched, due to the flow [Rolón-Garrido and Wagner (2007)]. In the Gaussian approximation considered here, $f_{\max }$ represents the maximum reduction in the tube diameter corresponding to the maximum stretch of chain segments, and equivalently $f_{\max }^{2}$ represents the maximum strain energy which can be stored in the polymeric system in nonlinear deformation. For more details about the derivation of the MSF model for polydisperse branched random polymer melts, see Wagner et al. (2001, 2003, 2004)

\section{RESULTS}

\section{A. Gel permeation chromatography}

In Fig. 2, the changes in the MWD are illustrated for both $1 \mathrm{C}$ and $2 \mathrm{C}$ degraded samples. For 1C samples [Fig. 2(a)], an increase in the degradation time leads to a shift of the MWD toward lower molecular weights as a result of chain scission, with the exception of LDPE 060 and LDPE 075, where the MWDs seem to overlap. For LDPE O90, not only the strongest increase in the low molecular weight population is observed, indicating the intensity of the chain scission effect, but also a significant increase of the high molecular weight tail.

In the case of $2 \mathrm{C}$ samples [Fig. 2(b)], the MWDs of LDPE O45+15 and LDPE O45+30 almost overlap with LDPE O45+0, as if almost no further structural modification occurs during the second cycle. However, a clear reduction in molar mass is observed in the case of LDPE O45+45. In contrast to the 1C samples, all $2 \mathrm{C}$ samples show the same high molecular weight tail, which also agrees with the high molecular weight tail of LDPE-T0 measured after storage of 3 months.

The contrast between the $1 \mathrm{C}$ and the $2 \mathrm{C}$ samples is presented in Fig. 2(c). The overlap of LDPE T0 and LDPE T0 measured after storage of 3 months is expected, the small deviation observed may be considered as being within experimental uncertainty. In the case of the LDPE O45 and LDPE O45+0, a small but significant difference in the MWD 

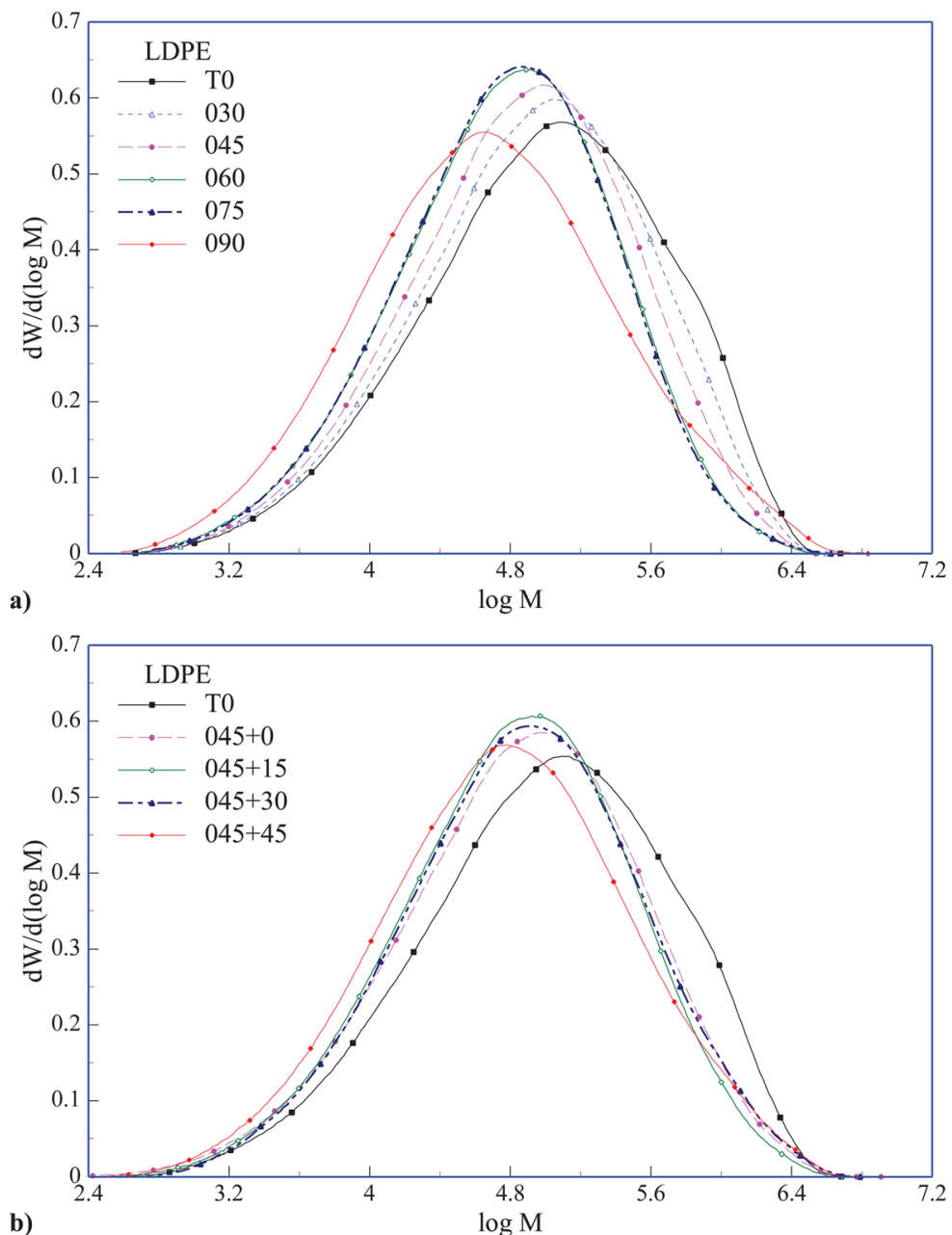

b)

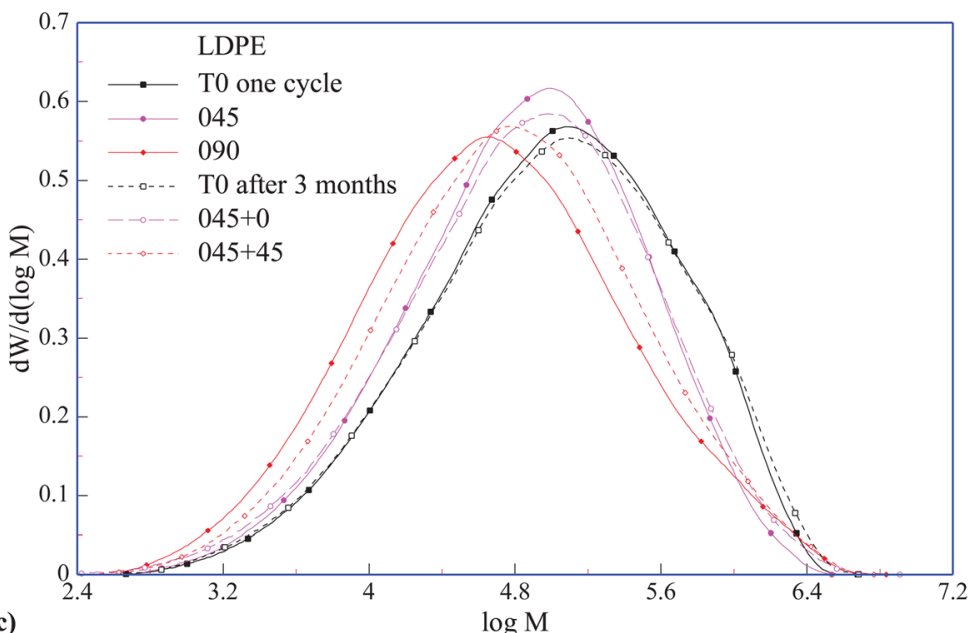

FIG. 2. Change in MWD for thermo-oxidative degraded samples in (a) one thermal cycle and (b) two thermal cycles. (c) Contrast between one and two cycle degraded samples. 
is observed, which indicates that the polymer after the first degradation (LDPE O45) contains already enough free radicals, which continue reacting at room temperature during the next 3 months (LDPE O45+0). The contrast in the MWDs of LDPE O90 and LDPE O45+45, both of which were degraded for $90 \mathrm{~min}$ in total, leads to the conclusion that thermo-oxidation is not an additive process.

The molecular characteristics $M_{\mathrm{w}}$ and $M_{\mathrm{w}} / M_{\mathrm{n}}$ as well as the intrinsic viscosity (iV) obtained from the chromatographic experiments are summarized in Fig. 3. In the case of $1 \mathrm{C}$ samples, $M_{\mathrm{w}}$ and $M_{\mathrm{w}} / M_{\mathrm{n}}$ decrease as the degradation time increases up to a degradation time of $75 \mathrm{~min}$, but for LDPE O90 a drastic increase is observed. For $2 \mathrm{C}$ samples, the tendencies are not as clear as for the $1 \mathrm{C}$ samples. The $\mathrm{iV}$ indicates also a reduction of molar mass with increasing degradation time. The higher iV of LDPE O45+45 in contrast to LDPE O90 is in agreement with the lack of a clear tendency as observed in Figs. 3(a) and 3(b).

\section{B. FTIR Spectroscopy}

The FTIR spectra obtained for both groups of samples are presented in Fig. 4. For 1C samples [Fig. 4(a)], there are regions where marked differences are noticed as the degradation time is increased. This effect is exemplified for the $1720-800 \mathrm{~cm}^{-1}$ region in Fig. 4(b), which has been amplified since here it is where structural differences due to branching can be observed [Pages et al. (1996); Carrasco et al. (2001)]. It is worth mentioning that although FTIR allows detecting the formation of branches, it does not permit to establish if the branches created are long or not. Differences can also be observed around $3400 \mathrm{~cm}^{-1}$, the region of absorption bands of hydroperoxides, which together with carbonyl groups are the typical oxidation products from thermo-oxidative degradation of polyethylene [Gugumus (1996a)]. This effect is stronger for the 1C samples [Fig. 4(a)] than for the $2 \mathrm{C}$ ones [Fig. 4(c)]. In fact, the spectra of the $2 \mathrm{C}$ samples show almost no difference at first glance but a closer look at the region from 1720 to $800 \mathrm{~cm}^{-1}$ [Fig. 4(d)] demonstrates that as in the case of the 1C samples, the absorption is enhanced at longer the degradation times.

Figure 5 presents the data of carbonyl index and the double bond index, as described in Sec. II B. Both indices are of the same order of magnitude and increase for both groups of samples. Although this tendency is less clear for the $1 \mathrm{C}$ samples, when comparing the ratios of the absorption bands measured for LDPE O90 to LDPE T0, and of LDPE O45+45 to LDPE O45, we notice that the double bond index does not change as dramatic as the carbonyl index, which changes more than 2.5 times more for the $1 \mathrm{C}$ than the $2 \mathrm{C}$ samples. This confirms the effectiveness of thermo-oxidative treatment for both groups of samples.

To discuss the differences observed between the $1 \mathrm{C}$ and the $2 \mathrm{C}$ samples in more detail, it should be stressed that the thermo-oxidative degradation is an autocatalytic free radical reaction [Schnabel (1981); Gugumus (1996a)], where the term autocatalytic should be understood as a reaction that starts slowly and accelerates with increasing concentration of the resulting peroxides [Kriston (2010)]. This may explain why it takes $45 \mathrm{~min}$ before an increase in the carbonyl index is observed in the $1 \mathrm{C}$ samples, and why the magnitude of increment, when comparing the increase from LDPE T0 to LDPE O45 is close to the increase seen between LDPE O45+0 and LDPE O45+45. In other words, the magnitude of the carbonyl index in LDPE O90 is higher than in LDPE O45+45, because while in LDPE O90 the autocatalytic effect is active, in the case of the LDPE O45+45 sample the autocatalytic reaction has not yet started effectively.

The bands related to chain branching present the same tendencies as in Fig. 5 with the growth being less marked for the $2 \mathrm{C}$ samples than for $1 \mathrm{C}$ group. The bands associated 


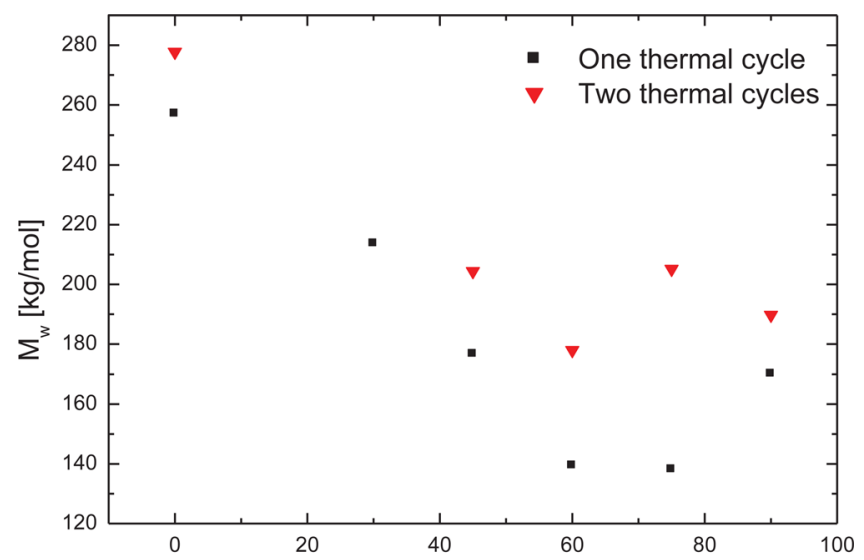

a)

$t_{\mathrm{deg}}[\mathrm{min}]$

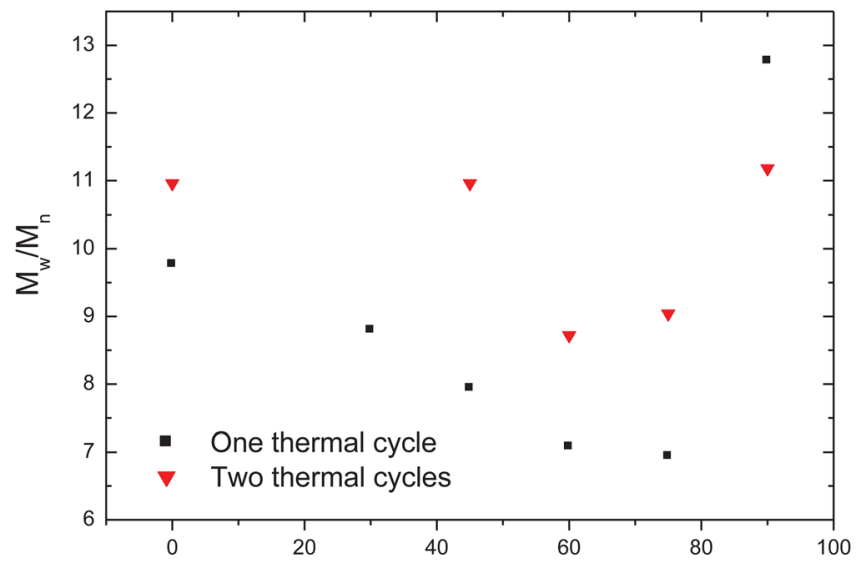

b)

$\mathrm{t}_{\mathrm{deg}}[\mathrm{min}]$

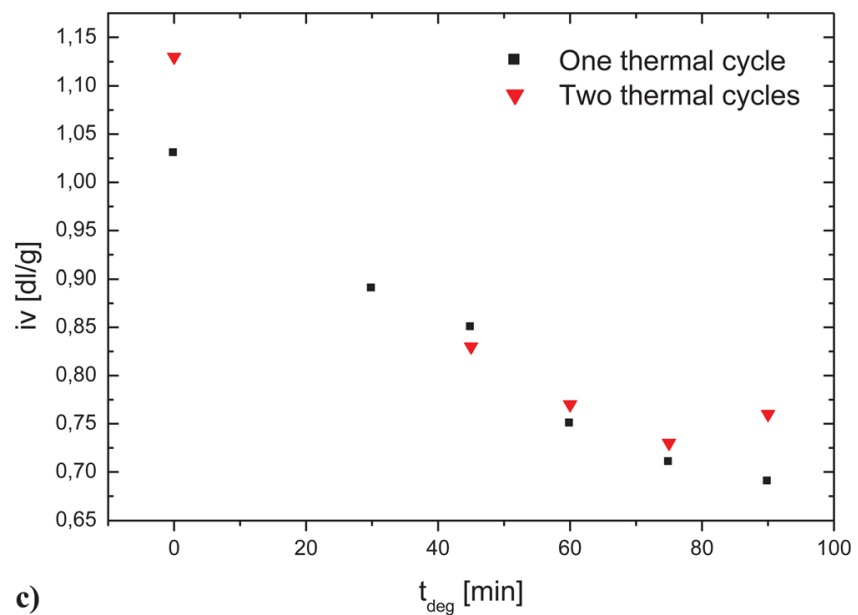

FIG. 3. Change in (a) weight average molecular weight, (b) polydispersity, and (c) intrinsic viscosity as a function of the total degradation time for the samples thermo-oxidativelly treated in one (closed symbols) and two (open symbols) thermal cycles. The results are presented as a function of the cumulative thermo-oxidative degradation time. 


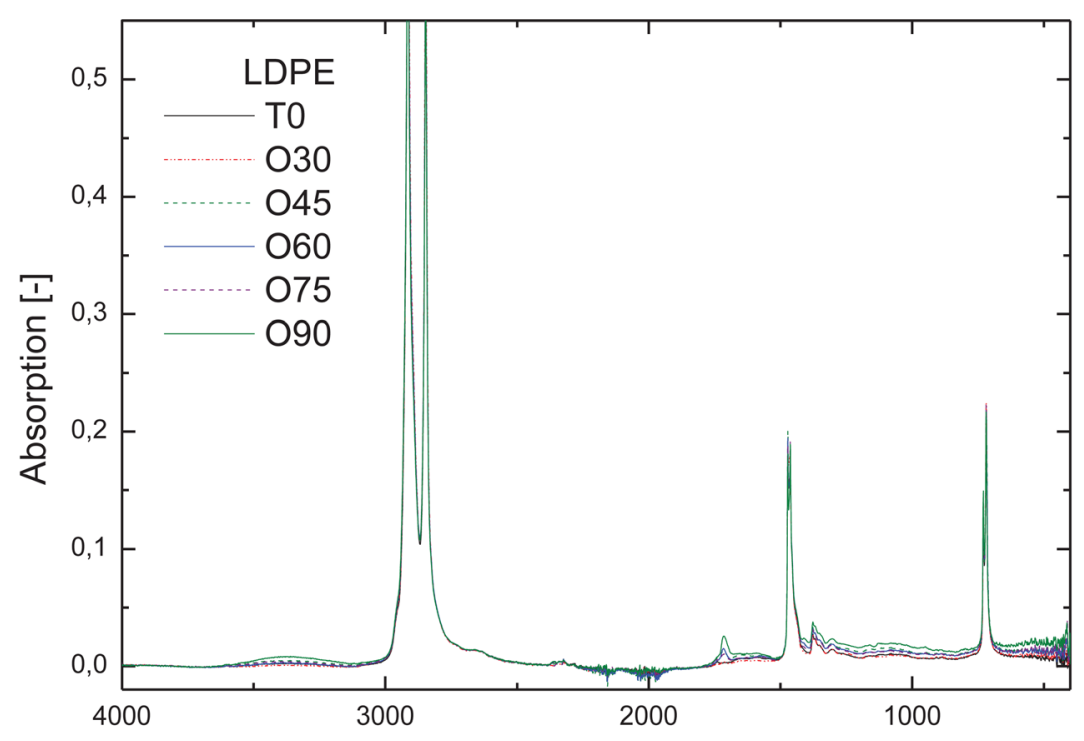

a)
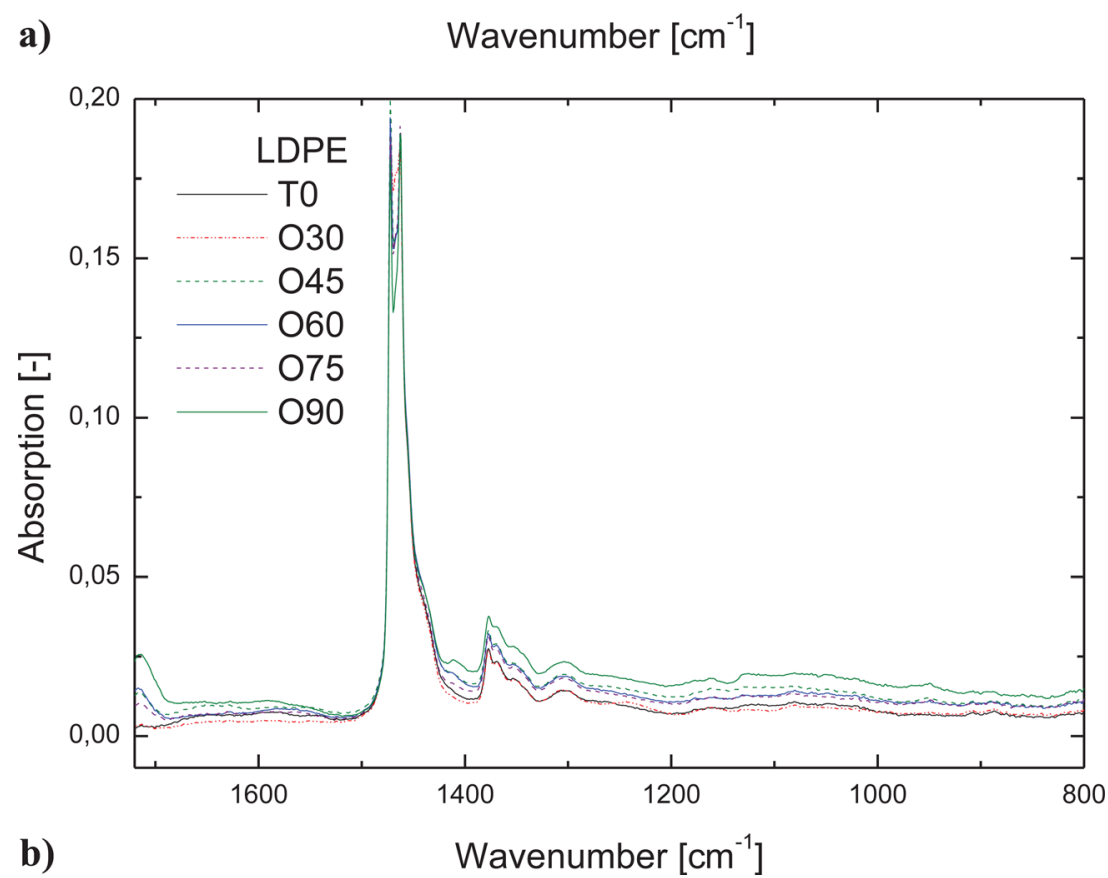

FIG. 4. Differences in the IR absorption spectrum for the treated samples in (a) one thermal cycle and (b) the region influenced by branching; and (c) two thermal cycles and (d) the region influenced by branching.

with vinyl groups (909 and $\left.990 \mathrm{~cm}^{-1}\right)$ and secondary alkyl group $\left(1177 \mathrm{~cm}^{-1}\right)$ were more affected than the tertiary alkyl group $\left(1368 \mathrm{~cm}^{-1}\right)$ or methyl group $\left(1375 \mathrm{~cm}^{-1}\right)$. The strongest increment was observed in the isolated hydroperoxides $\left(3550 \mathrm{~cm}^{-1}\right)$ and associated hydroperoxides $\left(3410 \mathrm{~cm}^{-1}\right)$, which are crucial in causing chain branching degeneration [Fodor et al. (1991)]. Furthermore, the autocatalytic effect has been shown before for the 909 and $3410 \mathrm{~cm}^{-1}$ bands in LDPE [Broska and Rychlý (2001)] and for 3550 and $3410 \mathrm{~cm}^{-1}$ in high density and linear low-density poleythylenes [Corrales et al. (2002)]. It has been also reported that alkyl radical can add to vinyl groups leading to branched 

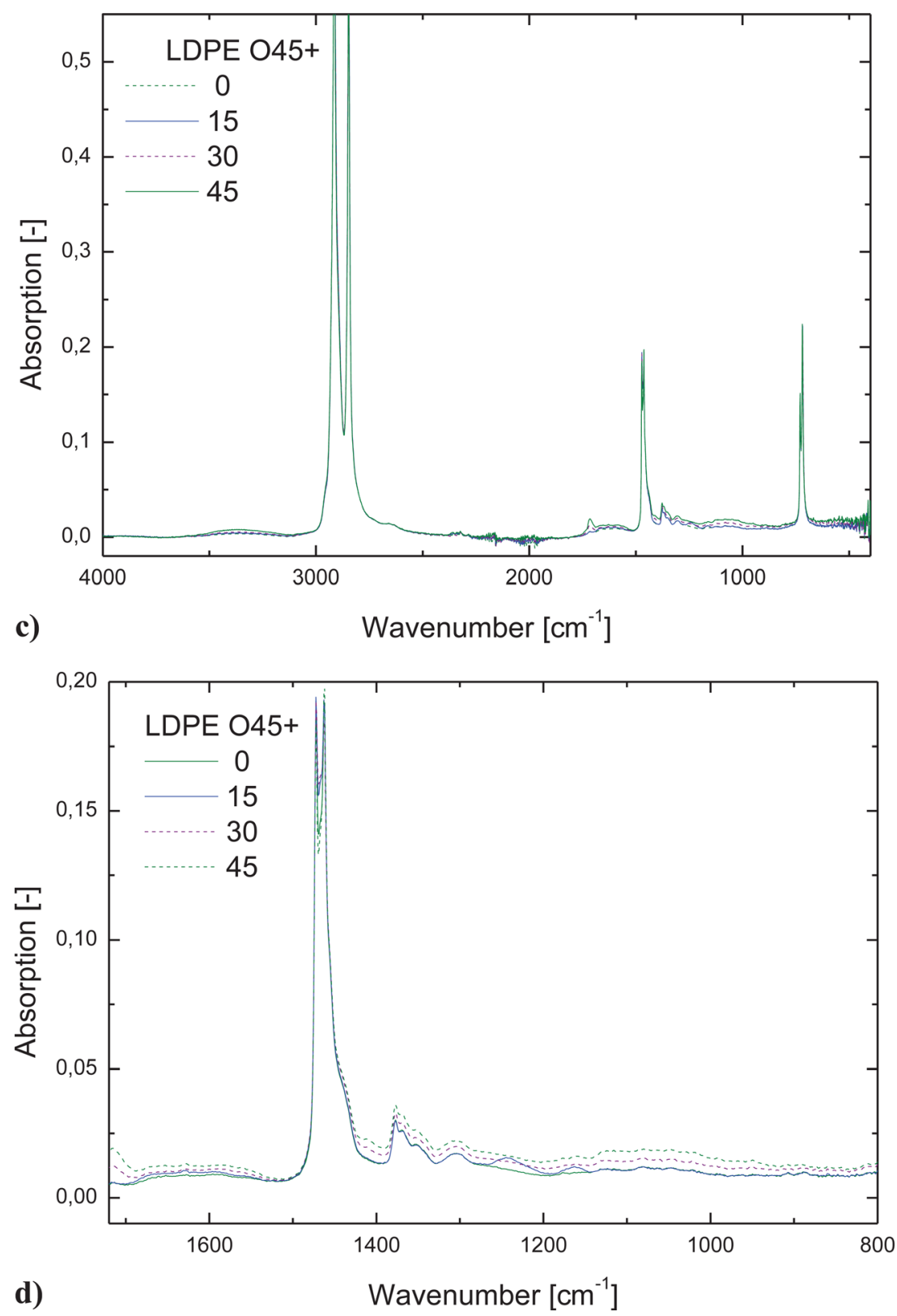

FIG. 4. (Continued).

and later to cross-linked molecules [Hinsken et al. (1991)]. Cross-linking is discarded here based on the linear-viscoelastic information.

Nevertheless, we do not compare the absolute values of every index and specific bands between the both groups, because the specific content of the short and long-chain branches is not known, and it is not known how this content is changed by a second degradation cycle.

Furthermore, the absorption bands associated with crystallinity, i.e., at 720, 730, 1474, and $1464 \mathrm{~cm}^{-1}$, or the ratio of the bands 730/720 [Pages et al. (1996); Carrasco et al. (2001)] do not show any clear tendency and therefore they are not presented here. This is 


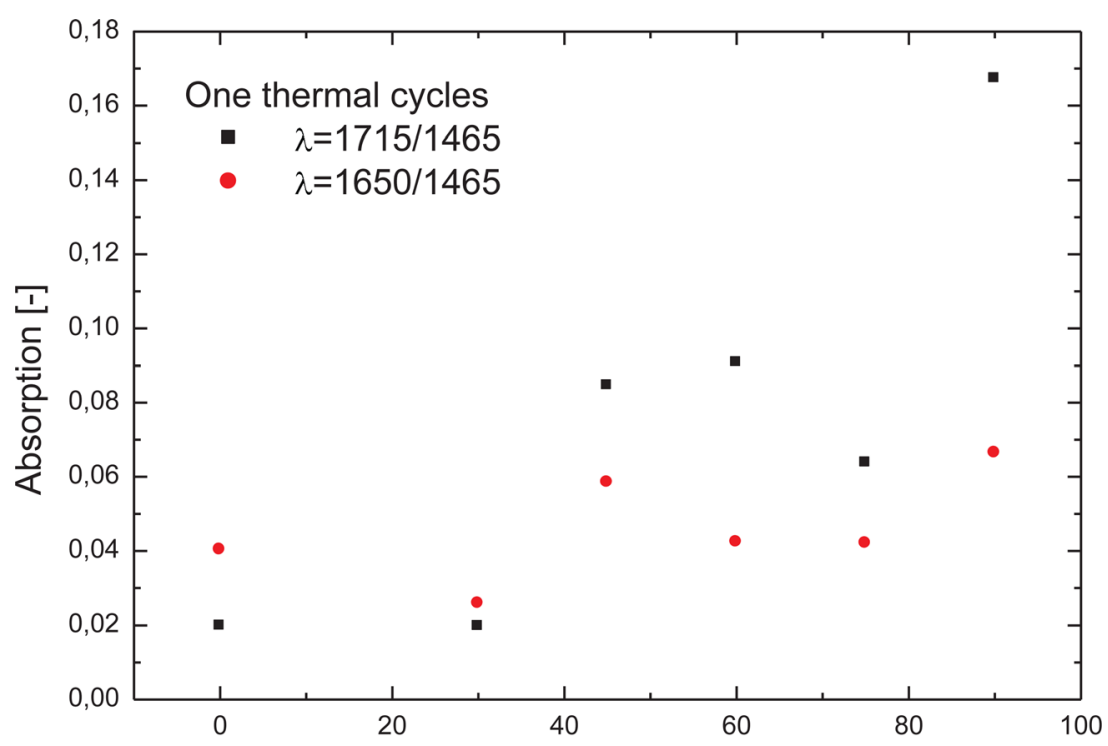

a)

$t_{\text {deg }}[\mathrm{min}]$

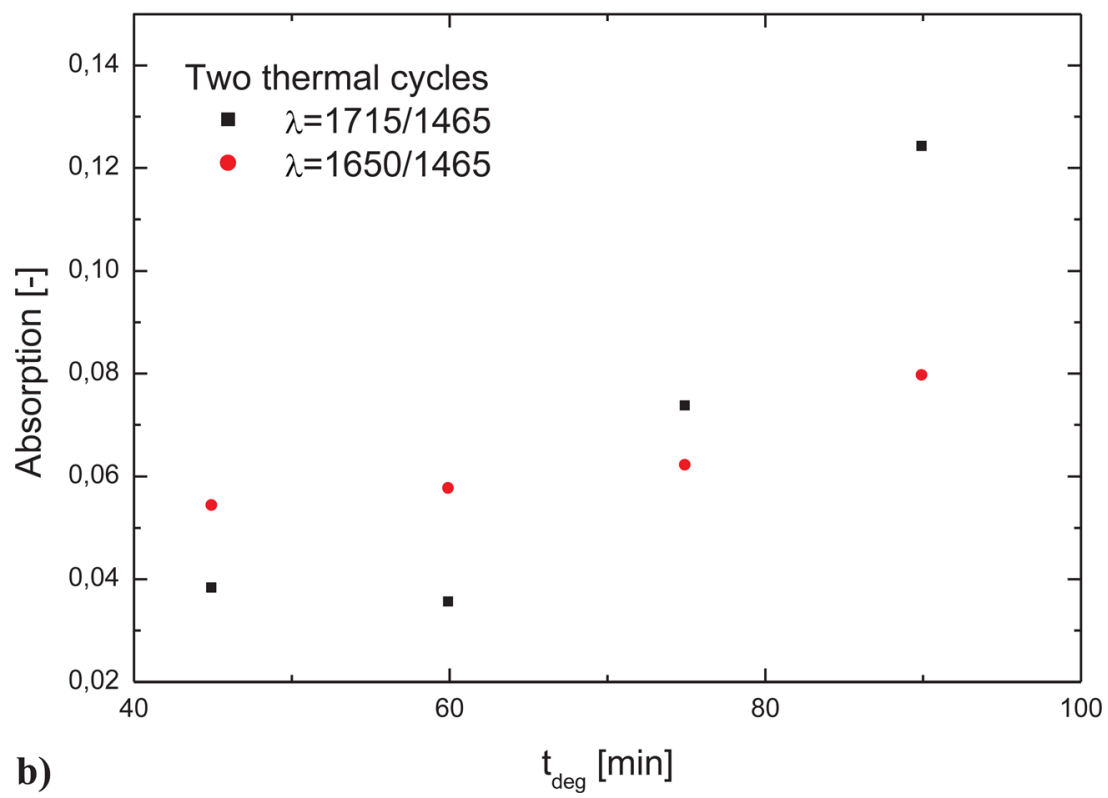

FIG. 5. Carbonyl (squares) and double bond (circles) indices for samples with (a) one and (b) two thermal cycles. The results are presented as a function of the cumulative thermo-oxidative degradation time.

in agreement with the similarity of the DSC results of degraded and reference samples as already mentioned in Sec. II B.

\section{Characterization by elongational rheology}

Elongational viscosities of the thermo-oxidatively degraded samples are presented in Figs. 6 and 7 for $1 \mathrm{C}$ and $2 \mathrm{C}$ samples, respectively. At each elongation rate, generally at least three measurements are reported, and excellent agreement is seen demonstrating the 

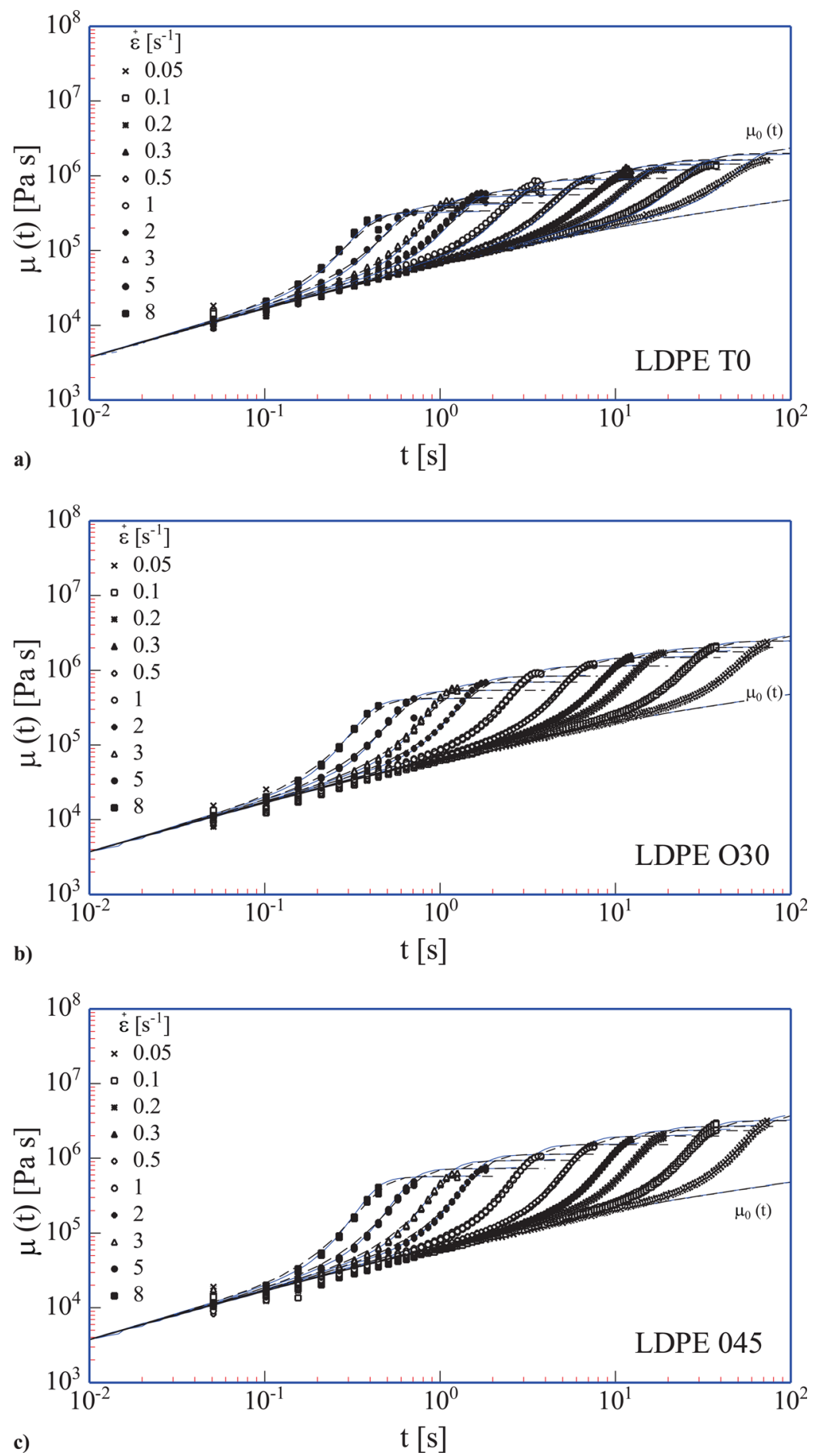

FIG. 6. Comparison between experimentally determined transient uniaxial elongational viscosity data of thermo-oxidatively degraded samples and predictions of MSF (continuous lines) and Wagner-I (dashed lines) models for the group treated in one thermal cycle at $170^{\circ} \mathrm{C}$. (a) LDPE T0, (b) LDPE O30, (c) LDPE O45, (d) LDPE O60, (e) LDPE O75, and (f) LDPE O90. The linear-viscoelastic start up is respresented by the $\mu_{0}(t)$ lines. 

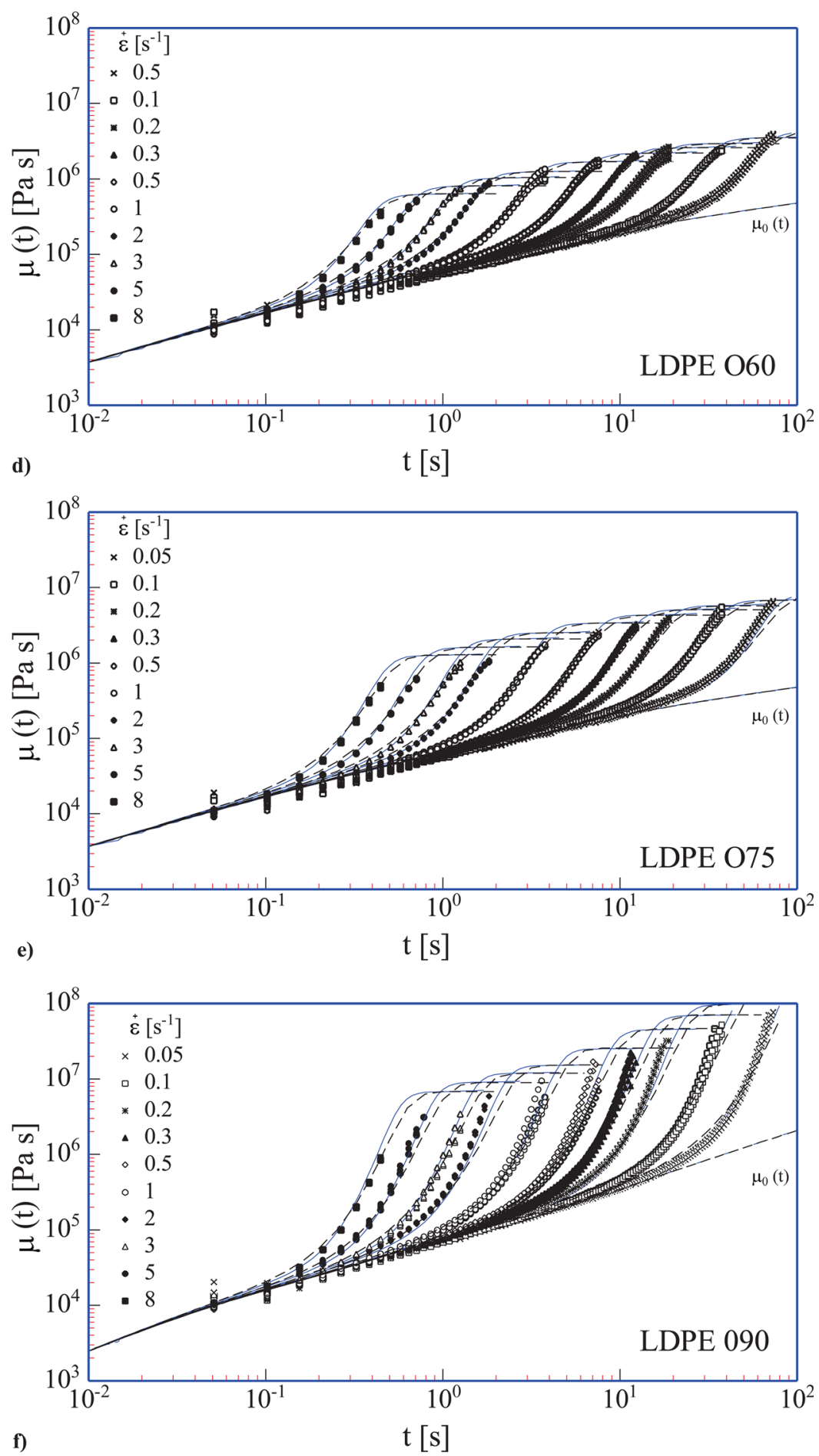

FIG. 6. (Continued). 

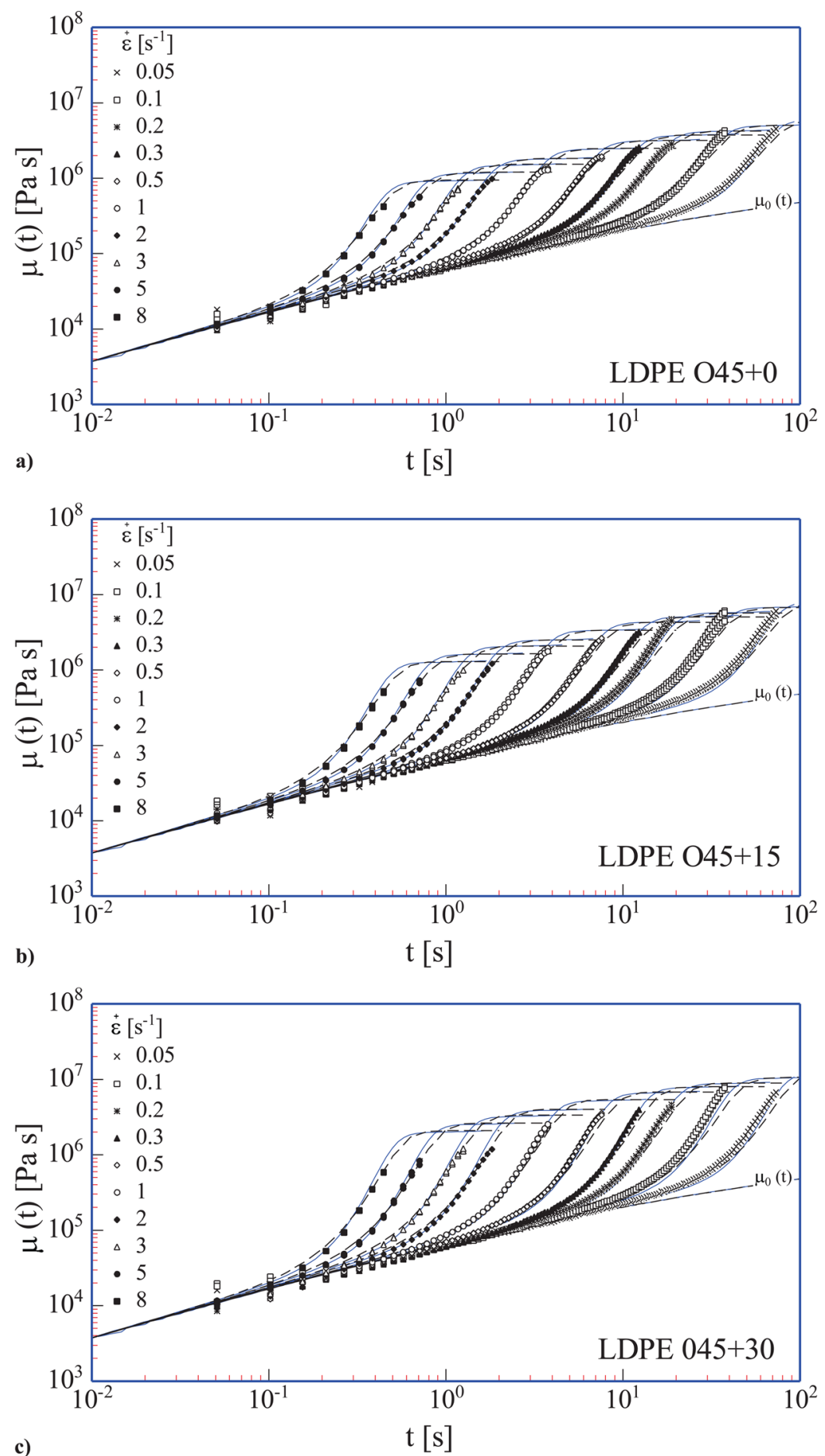

FIG. 7. Comparison between experimentally determined transient uniaxial elongational viscosity data of thermo-oxidatively degraded samples and predictions of MSF (continuous lines) and Wagner-I (dashed lines) models for the group treated in two thermal cycles at $170^{\circ} \mathrm{C}$. (a) LDPE O45+0, (b) LDPE O45+15, (c) LDPE $\mathrm{O} 45+30$, (d) LDPE O45+45. The linear-viscoelastic start up is respresented by the $\mu_{0}(t)$ lines. 


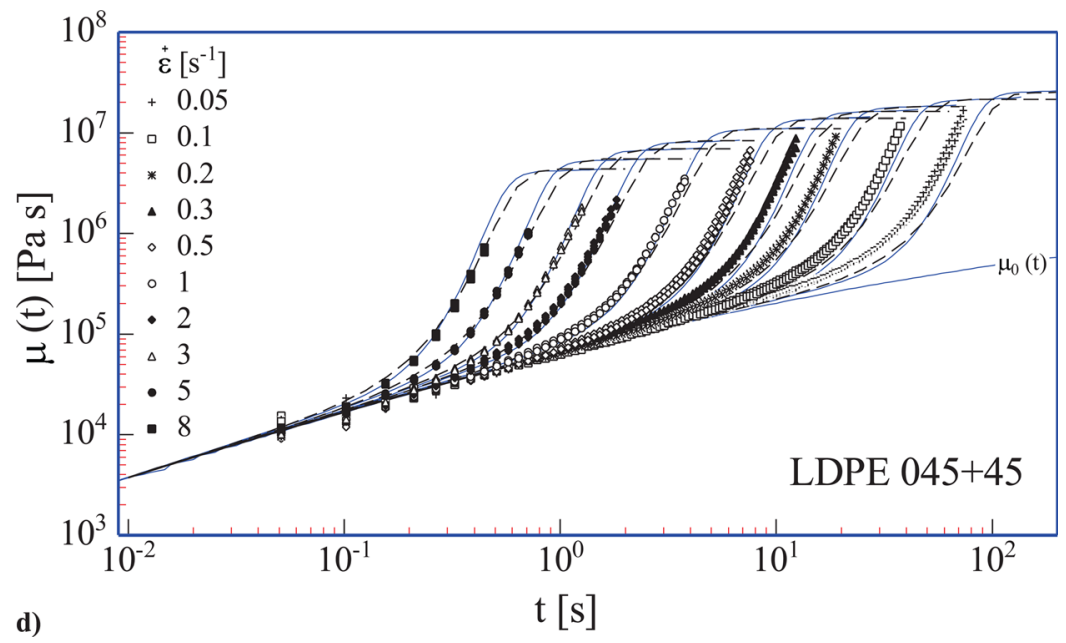

FIG. 7. (Continued).

reproducibility achieved with the SER-2 platform. Good agreement is observed between the experimental data of the start-up of elongational flow and the zero-rate elongational viscosity $\mu_{0}(t)$, calculated from the viscoelastic spectral data of the reference sample, except for sample LDPE O90. This is in accordance with the results obtained previously with another LDPE grade, where we demonstrated that the thermo-oxidative process affects mainly the nonlinear rheological response while the linear-viscoelastic regime remains almost unaffected [Rolón-Garrido et al. (2011a)]. For LDPE O90, we noticed that the experimental start-up viscosity differs indeed significantly from the other samples. However, the zero-rate elongational viscosity $\mu_{0}(t)$ of LDPE O90 can be modeled with a relaxation spectrum obtained by using a Levenberg-Marquardt routine (see Sec. II B and Table I).

Considering the results in the nonlinear regime, the modeling was carried out in such a way that first the nonlinear parameters of the MSF model were fitted to the experimental data, and then the free parameters of the Wagner-I model were chosen to overlap, as much as possible, the MSF predictions. Since the LDPE analyzed here is produced by tubular reactor technology [Resch (2010)], a value of $\beta=2.0$ was found for LDPE T0 in accordance with previous MSF model results [Wagner et al. (2003)]. Indeed also for all degraded samples the parameter $\beta$ turned out to be equal to 2 , which can be interpreted as an indication that chain scission and LCB formation occur in such a way that more but shorter long-chain branches are obtained or, in other words, that the mass of the entangled branches remains on average equal to the mass of the effective backbone, and consequently the type of random branching structure remains unchanged by thermal degradation [Rolón-Garrido et al. (2011a)]. The MSF model parameter $\beta$ determines the slope of the time-dependent elongational viscosity after the beginning of strain hardening [Wagner et al. (2003)]. In the Wagner-I model, this role is played by the parameter $m$ : The smaller or larger the value of $m$ is, the stronger or weaker is the strain hardening predicted. A value of $m=0.038$ was found to be optimal for all samples. Therefore for each model, only one nonlinear parameter remains to describe the differences in the strainhardening potential seen for the different samples, $f_{\max }^{2}$ (MSF model) and $a$ (Wagner-I model). The nonlinear parameters used for the simulations presented in Figs. 6 and 7 are summarized in Table II. 
TABLE II. Nonlinear parameters used for the simulations performed.

\begin{tabular}{|c|c|c|c|c|c|}
\hline \multirow[b]{2}{*}{ Group sample } & \multicolumn{2}{|c|}{ One thermal cycle } & \multirow[b]{2}{*}{ Group sample } & \multicolumn{2}{|c|}{ Two thermal cycles } \\
\hline & $\begin{array}{c}f_{\max }^{2} \\
\beta=2.0\end{array}$ & $\begin{array}{c}a \\
m=0.038\end{array}$ & & $\begin{array}{c}f_{\max }^{2} \\
\beta=2.0\end{array}$ & $\begin{array}{c}a \\
m=0.038\end{array}$ \\
\hline LDPE T0 & 24 & 0.0076 & & & \\
\hline LDPE 030 & 32 & 0.0059 & & & \\
\hline LDPE 045 & 45 & 0.0042 & LDPE $045+0$ & 77 & 0.0024 \\
\hline LDPE 060 & 51 & 0.0037 & LDPE $045+15$ & 110 & 0.0017 \\
\hline LDPE 075 & 110 & 0.0017 & LDPE $045+30$ & 180 & 0.0010 \\
\hline LDPE 090 & 500 & $3.8 \times 10^{-4}$ & LDPE $045+45$ & 400 & $4.5 \times 10^{-4}$ \\
\hline
\end{tabular}

The $f_{\max }^{2}$ parameters observed would correspond to a maximum stretch of 4.89 for LDPE T0, of 22.36 for LDPE O90, and of 20 for LDPE O45+45 based on Gaussian chain statistics. A similar trend was observed for thermo-oxidatively degraded samples reported earlier [Rolón-Garrido et al. (2011a)].

In general, the agreement of experimental data and model predictions is excellent. The discrepancy noticed at the lowest elongational rate in the case of LDPE O45+45 [Fig. 7(d)] may be an indication that the use of the relaxation spectrum of LDPE T0 to describe the linear-viscoelasticity of the thermo-oxidativly degraded samples has its limitations in this case. In fact, the deviation has its origin in the lack of longer relaxation times than the one included in the spectrum of LDPE T0, due to a higher LCB content of LDPE O45+45 in contrast to LDPE T0.

As seen from Figs. 6 and 7, there is no doubt that thermo-oxidative degradation modifies the molecular structure in a stronger way, the higher the exposure time is. As far as the modelling is concerned, it can be stated that both models are capable of describing quantitatively the experimental results. While $f_{\max }^{2}$ increases the stronger the strain hardening is, the nonlinear parameter $a$ decreases. $f_{\max }^{2}$ and $a$ are presented as a function of the cumulative thermal oxidation time in Fig. 8.

Figure 8(a) also includes ealier results of the effect of thermo-oxidative degradation of LDPE 3020D in 1C [Rolón-Garrido et al. (2011a)]. Since both LDPE grades are produced by the same tubular technology, it is expected that both samples possess a similar comb-type branched structure. Nevertheless, the density values given by the producer of $919 \mathrm{~kg} / \mathrm{m}^{3}$ for LDPE $1840 \mathrm{D}$ and $926 \mathrm{~kg} / \mathrm{m}^{3}$ for LDPE 3020D indicate a higher LCB content in LDPE 1840D than in LDPE 3020D. Therefore, LDPE 1840D shows a higher strain-hardening potential, reflected by higher values of $f_{\max }^{2}$ already in the reference sample LDPE 1840D, than that of LDPE 3020D. We also notice a difference in the change of $f_{\max }^{2}$ with increasing degradation time: While an extreme increase in $f_{\max }^{2}$ is observed for LDPE O90 based on LDPE 1840D, a decrease was found for LDPE 3020D after a degradation time of $90 \mathrm{~min}$, when the effect of chain scission overcomes the creation of additional LCB. This difference may have its origin in the fact that LDPE 1840D contains more branch points than LDPE 3020D, and branch points of polyethylene are considered as one of the weak link structures, from which thermally induced chain scission and radical formation can start [Peterson et al. (2001)]. Therefore under the condition of thermooxidative degradation, LDPE $1840 \mathrm{D}$ is more reactive than LDPE $3020 \mathrm{D}$, and LCB formation dominates chain scission. The strong strain hardening observed for LDPE O90 is also in agreement with the increase in the content of high molecular weight species as measured by GPC, since it has been reported that high molar mass components can influence strongly the elongational viscosity [Münstedt (1980)]. 

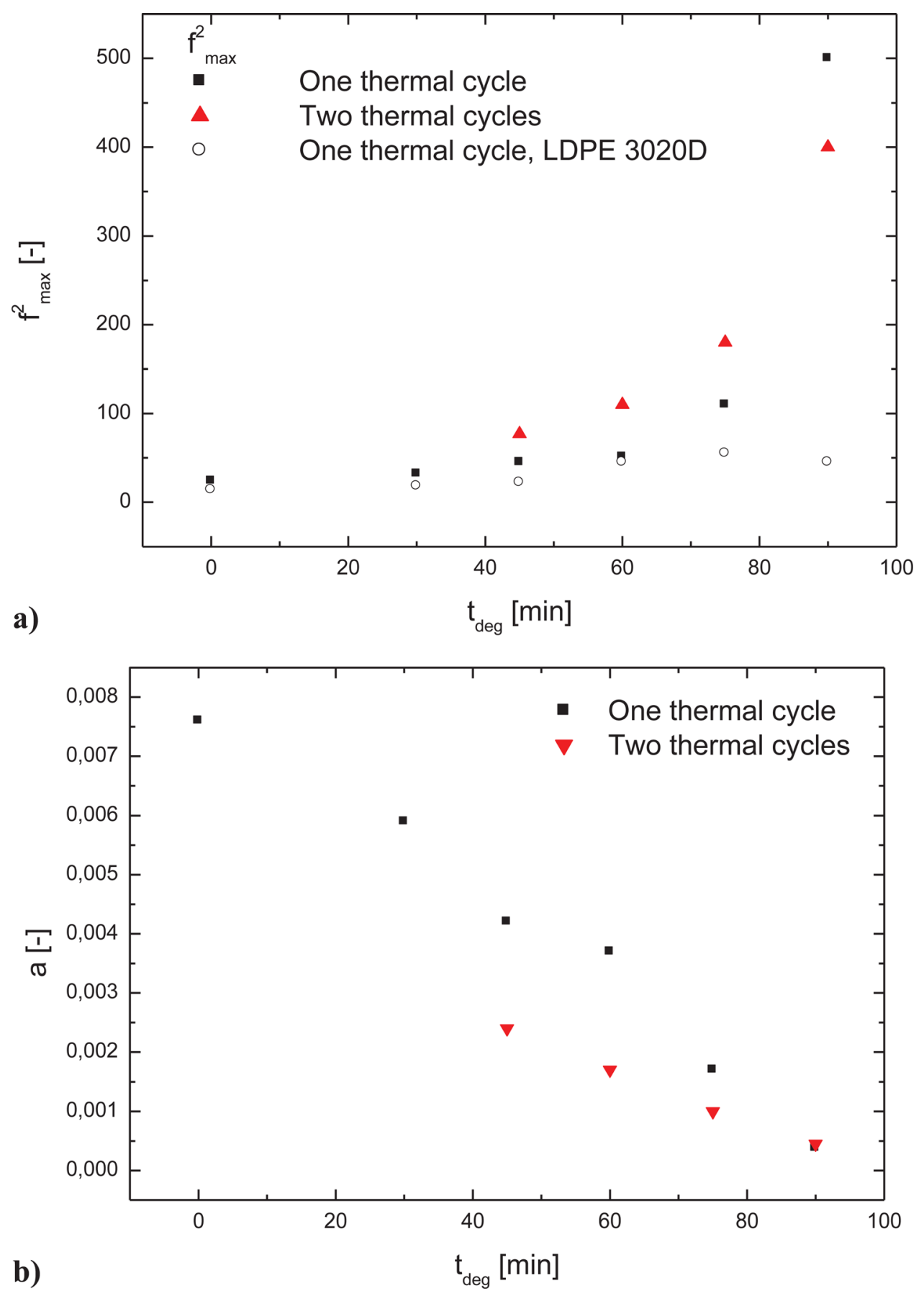

FIG. 8. Nonlinear parameter of the (a) MSF model including the result obtained for LDPE 3020D in RolónGarrido et al. (2011a) and (b) Wagner-I constitutive equation as a function of the cumulative thermo-oxidative degradation time. 

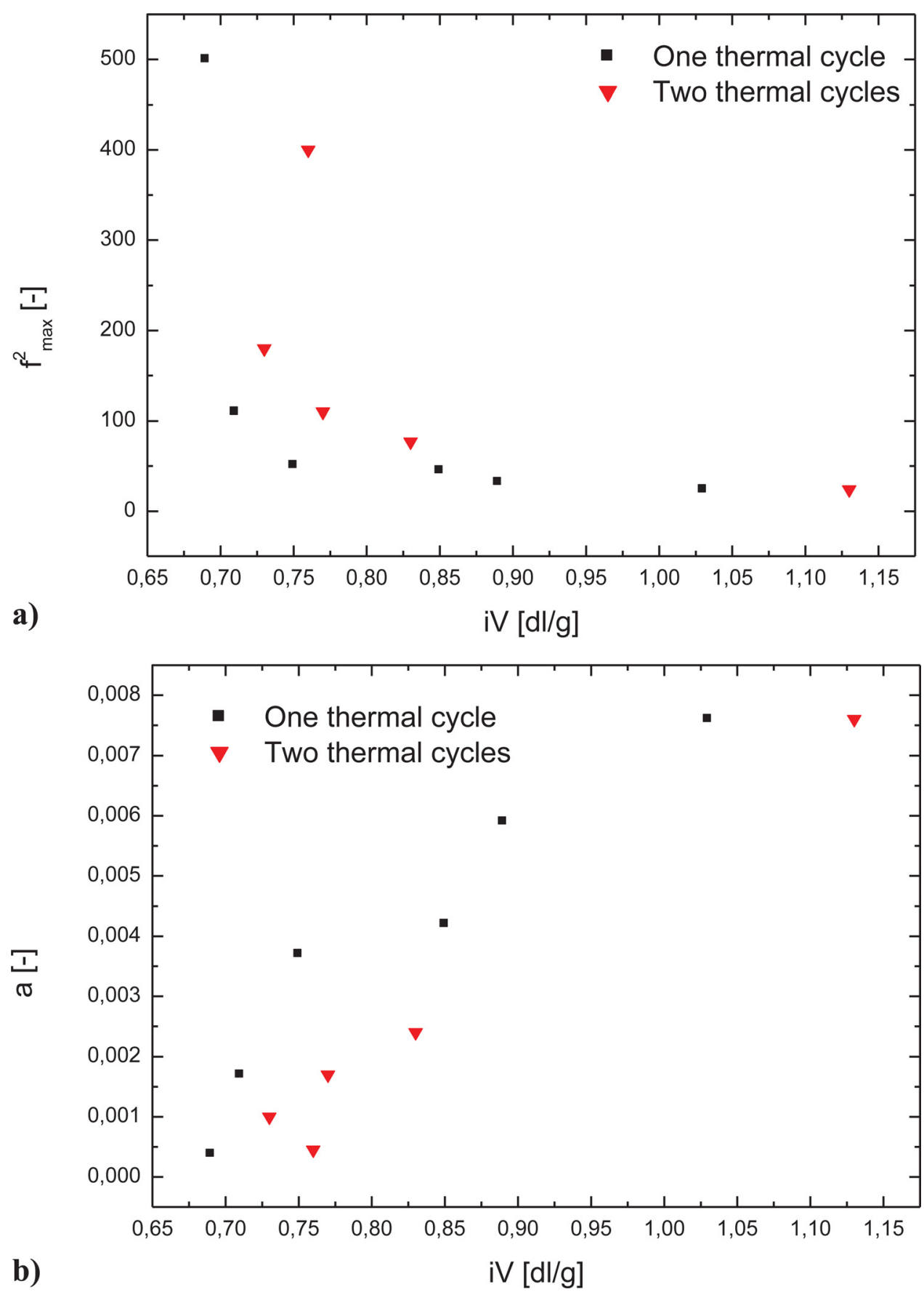

FIG. 9. Nonlinear parameter of the (a) MSF model and (b) Wagner-I constitutive equation as a function of the measured intrinsic viscosity.

Figure 8 (a) also presents the $f_{\max }^{2}$ values obtained for the $2 \mathrm{C}$ samples. It is worth remembering that the second thermal treatment was done after 3 months of the first thermal cycle. The first point to stress is the considerable higher value of $f_{\max }^{2}$ of LDPE $\mathrm{O} 45+0$ than that of LDPE O45. Taking into account the reproducibitly obtained with the 
SER-2, this difference can be considered to be outside experimental uncertainties. The increase in strain-hardening potential may be due to active radicals produced during the first thermal cycle, which caused further structural modifications during the 3 months of storage of the sample at room temperature conditions. LDPE O $45+15$ features the same $f_{\max }^{2}$ value as LDPE O75, while more than a $50 \%$ difference in $f_{\max }^{2}$ is observed between LDPE $\mathrm{O} 75$ and the $2 \mathrm{C}$ sample with the same cumulative degradation time, LDPE O45+30. However, the level of $f_{\max }^{2}$ for LDPE O45+45 is lower than for LDPE O90, which is in agreement with the carbonyl index as determined by FTIR. This shows that thermal-oxidative degradation is not a linearly additive process if it is performed in two steps, and that the kinetics of chain scission and LCB formation initiated by thermooxidative treatment is complex, as also confirmed by the GPC results [see Fig. 2(c)].

Futhermore, the bands associated with chain branching measured by FTIR also agree with a smaller value of $f_{\max }^{2}$ for LDPE O45+45 than for LDPE O90. It is worth mentioning that the rate of oxygen absorption and the rate of formation of chemical reaction products increase overproportionally with exposure time due to the expected autocatalytic effect [de Bruijn (1996)]. A long induction time for a drastic increase of $f_{\max }^{2}$ is observed in Fig. 8(a) for the 1C samples probably due to the presence of antioxidants in the commercial LDPE investigated here. Although the rate of change is more pronounced for the $2 \mathrm{C}$ samples, probably a second oxidation cycle of only $45 \mathrm{~min}$ is not long enough in LDPE O45+45 for producing the same structural changes as in LDPE O90, due to the induction time required to start the reaction in agreement with the discussion of the FTIR results. This is also in agreement with the fact that the linear-viscoelastic properties of LDPE O45+45 are similar to the reference sample, but not to those of LDPE O90. The model parameter $a$ of the Wagner-I model shows a more or less linear decrease with increasing degradation time for both $1 \mathrm{C}$ and $2 \mathrm{C}$ samples [Fig. 8(b)].

Since the nonlinear parameters $f_{\max }^{2}$ and $a$ are directly related to the structure of the sample, their magnitude can be compared with other characteristic quantities also related to the structure and measured by other techniques such as GPC (Fig. 9). We find clear correlations between the iV and the model paramters $f_{\max }^{2}$ [Fig. 9(a)] and $a$ [Fig. 9(b)], with a decreasing iV being correlated to an increasing strain-hardening potential. This correlation has been observed before by considering the coil contraction factor and its effect on $\mathrm{iV}$ in the case of model comb polystyrene samples [Rolón-Garrido and Wagner (2007)].

Since FTIR does not allow distinguishing between long and short chain branches, no comparison is performed between $f_{\max }^{2}$ and specific bands.

\section{CONCLUSIONS}

LDPE $1840 \mathrm{D}$ was thermo-oxidatively degraded at $170^{\circ} \mathrm{C}$ in the presence of air in socalled $1 \mathrm{C}$ experiments for times between 30 and $90 \mathrm{~min}$, and also during $2 \mathrm{C}$ experiments, i.e., an already previously for $45 \mathrm{~min}$ degraded sample plate was further degraded after 3 months of storage at room temperature and pressure during times between 15 and $45 \mathrm{~min}$. Samples were then characterized by GPC, FTIR spectroscopy, and rheology. The elongational viscosities measured were analyzed in the framework of the MSF and the WagnerI models. Thermo-oxidative treatment leads first to continuous reduction of molar mass $M_{\mathrm{w}}$ as determined by GPC, followed by an increase at the longest degradation time. iV measurements indicate also a reduction of molar mass with increasing degradation times for both $1 \mathrm{C}$ and $2 \mathrm{C}$ samples. Thermo-oxidative treatment is associated with an increase of the carboxyl and double bond indices as determined from FTIR measurements, and 
the additional formation of branches as indicated by the absorption enhancement at longer the degradation times in the region between 909 and $1653 \mathrm{~cm}^{-1}$ for $1 \mathrm{C}$ and $2 \mathrm{C} \mathrm{sam}$ ples. Uniaxial extension experiments show a strong increase in the strain-hardening potential for both $1 \mathrm{C}$ and $2 \mathrm{C}$ samples, which is indicative of a strong increase in LCB content. Linear viscoelasticity seems to be hardly affected by the thermo-oxidative exposure, with the exception of the longest degradation time for the $1 \mathrm{C}$ sample. The nonlinear parameter $\beta$ of the MSF model was found to be $\beta=2$ for all samples, indicating that the general type of the random branching structure remains the same under all degradation conditions. Equally, the nonlinear parameter $m$ of the Wagner-I model was constant for all samples. Therefore, only one nonlinear parameter per model was necessary to describe the elongational viscosity data quantitatively. While the $f_{\max }^{2}$ parameter of the MSF model increases overproportionally for both 1C and 2C samples with increasing degradation times, the parameter $a$ of the Wagner-I model decreases linearly. By comparing the results for $1 \mathrm{C}$ and $2 \mathrm{C}$ samples, we notice that the thermo-oxidative degradation is not a linearly additive process. This may be due to the autocatalytic character of the reaction which is confirmed by both FTIR and elongational rheology. An induction time seems to be necessary to start the degradation process.

Considering the different experimental techniques applied, GPC confirms chain scission and a change of the MWD which is not proportional to the time of thermo-oxidative degradation. FTIR results point to the autocatalytic character of the thermo-oxidative process, explaining the differences in LCB content as observed by the rheology results and quantified by the parameters $f_{\max }^{2}$ and $a$ of the MSF and Wagner-I model, respectively. Additionally, FTIR results confirm that the thermo-oxidation occurs through the whole sample and not only on the surface in contact to air.

Therefore, although all techniques applied indicate that modifications occur in the samples, it can be concluded that elongational rheology is a very sensitive and powerful method to detect structural changes due to thermo-oxidative degradation, especially the formation of enhanced LCB. It has the further advantage that experimental data can be quantified by one nonlinear model parameter of constitutive equations like the MSF or the Wagner-I model.

\section{ACKNOWLEDGMENTS}

Financial support by the German Science Foundation (DFG), Grant Agency of the Czech Republic (Grant No. 103/09/2066) and Operational Program Research and Development for Innovations co-funded by the European Regional Development Fund (ERDF) and national budget of Czech Republic within the framework of project Centre of Polymer Systems (reg. number: CZ.1.05/2.1.00/03.0111) is gratefully acknowledged.

\section{References}

Abbasi, M., N. G. Ebrahimi, M. Nadali, and M. K. Esfahani, "Elongational viscosity of LDPE with various structures: Employing a new evolution equation in MSF theory," Rheol. Acta 51(2), 163-177 (2012).

Albertsson, A. C., S. O. Andersson, and S. Karlsson, "The mechanism of biodegradation of polyethylene," Polym. Degrad. Stab. 18, 73-87 (1987).

Arnett, R. L., and C. J. Stacy, "Kinetics of the thermal degradation of linear polyethylene," Polym. Eng. Sci. 6(4), 295-298 (1966).

Audouin, L., V. Langlois, J. Verdu, and J. C. M. de Bruijn, "Review. Role of oxygen diffusion in polymer ageing: Kinetic and mechanical aspects," J. Mater. Sci. 29, 569-583 (1994). 
Broska, R., and J. Rychlý, "Double stage oxidation of polyethylene as measured by chemiluminescence," Polym. Degrad. Stab. 72, 271-278 (2001).

Budrugeac, P., and E. Segal, "Changes in the mechanical properties and thermal behaviour of LDPE in response to accelerated thermal aging," J. Therm. Anal. 53, 801-808 (1998).

Carrasco, F., P. Pages, S. Pascual, and X. Colom, “Artificial aging of high-density polyethylene by ultraviolet irradiation,” Eur. Polym. J. 37, 1457-1464 (2001).

Cho, Y. S., M. J. Shim, and S. W. Kim, “Thermal degradation kinetics of PE by the Kissinger equation,” Mater. Chem. Phys. 52, 94-97 (1998).

Colin, X., L. Audouin, and J. Verdu, "Determination of thermal oxidation rate constants by an inverse method. Application of polyethylene," Polym. Degrad. Stab. 86, 309-321 (2004).

Corrales T., F. Catalina, C. Peinado, N. S. Allen, and E. Fontan, "Photooxidative and thermal degradation of polyethylenes: Interrelationship by chemiluminescence, thermal gravimetric analysis and FTIR data," J. Photochem. Photobiol., A 147, 213-224 (2002).

Crank, J., and G. S. Park, Diffusion in Polymers (Academic, London, 1968).

de Bruijn, J. C. M., "Degradation profiles of thick high-density polyethylene samples after outdoor and artificial weathering," Adv. Chem. Ser. 249, 599-620 (1996).

Doi, M., and S. F. Edwards, "Dynamics of concentrated polymer systems. Part 2-Molecular motion under flow," J. Chem. Soc., Faraday Trans. 2 74, 1802-1817 (1978).

Drozdov, A. D., "The effect of thermal oxidative degradation of polymers on their viscoelastic response," Int. J. Eng. Sci. 45, 882-904 (2007).

Epacher, E., J. Tolveth, C. Kröhnke, and B. Pukanszky, "Processing stability of high density polyethylene: Effect of adsorbed and dissolved oxygen," Polymer 41, 8401-8408 (2000).

Eriksson, T., and H. K. Rasmussen, "The effects of polymer melt rheology on the replication of surface microstructures in isothermal moulding," J. Non-Newtonian Fluid Mech. 127, 191-200 (2005).

Fodor, Z., M. Iring, and F. Tudos, "Correlation between oxygen uptake and carbonyl formation in polyethylene oxidation,” J. Macromol. Sci., Chem. 28(7), 641-650 (1991).

Gahleitner, M., "Melt rheology of polyolefins,” Prog. Polym. Sci. 26, 895-944 (2001).

Gijsman, P., "Review on the thermo-oxidative degradation of polymers during processing and in service," e-Polymers, Article Number 065 (2008).

Gillen, K. T., J. Wise, and R. L. Clough, "General solution for the basic autoxidation scheme," Polym. Degrad. Stab. 47, 149-161 (1995).

Gugumus, F., "Thermooxidative degradation of polyolefins in the solid state: Part 1. Experimental kinetics of functional group formation," Polym. Degrad. Stab. 52, 131-144 (1996a).

Gugumus, F., "Thermooxidative degradation of polyolefins in the solid state. Part 3: Heterogeneous oxidation model,” Polym. Degrad. Stab. 52, 159-170 (1996b).

Gugumus, F., "Re-examination of the thermal oxidation reactions of polymers 2. Thermal oxidation of polyethylene,” Polym. Degrad. Stab. 76, 329-340 (2002).

Hakkarainen, M., and A.-C. Albertsson, "Environmental degradation of polyethylene," Adv. Polym. Sci. 169, 177-199 (2004).

Hinsken, H., S. Moss, J. R. Pauquet, and H. Zweifel, "Degradation of polyolefins during melt processing," Polym. Degrad. Stab. 34(1-3), 279-293 (1991).

Holmström, A., and E. M. Sörvik, "Thermal degradation of polyethylene in a nitrogen atmosphere of low oxygen content. II. Structural changes occurring in low-density polyethylene at an oxygen content less than 0.0005\%,” J. Appl. Polym. Sci. 18, 761-778 (1974).

Holmström, A., and E. M. Sörvik, "Thermooxidative degradation of polyethylene. I and II. Structural changes occurring in low-density polyethylene, high-density polyethylene, and tetrateracontane heated in air," J. Polym. Sci., Polym. Chem. Ed. 16, 2555-2586 (1978).

Iring, M., F. Tudos, Z. Fodor, and T. Kelen, "The thermo-oxidative degradation of polyolefines-Part 10. Correlation between the formation of carboxyl groups and scission in the oxidation of polyethylene in the melt phase," Polym. Degrad. Stab. 2, 143-153 (1980).

Johnston, R. T., and E. J. Morrison, "Thermal scission and cross-linking during polyethylene melt processing," Adv. Chem. Ser. 249, 651-682 (1996). 
Koc, A., E. H. Simsek, and A. Y. Bilgesue, "Oxidative thermal degradation of LDPE and the determination of thermodynamic quantities,” J. Anal. Appl. Pyrolysis 85, 380-383 (2009).

Konar, J., and R. Ghosh, "Characterization of oxidized LDPE by solid state fluorescence spectra," J. Appl. Polym. Sci. 40, 719-729 (1990).

Kriston, I., "Some aspects of the degradataion and stabilization of Phillips type polyethylene," Ph.D. thesis, Budapest University of Technology and Economics, 2010, Budapest.

Kumar, G. S., V. R. Kumar, and G. Madras, "Continuous distribution kinetics for the thermal degradation of LDPE in solution,” J. Appl. Polym. Sci. 84, 681-690 (2002).

La Mantia, F. P., V. Citta, and A. Valenza, "Influence of low extents of degradation on the processing behaviour of high density polyethylene," Polym. Degrad. Stab. 23, 109-119 (1989).

Mariani, P., G. Carianni, F. Menconi, and F. P. La Mantia, "Correlation between processability and properties of a high density polyethylene by a rheological approach," Macromol. Chem. Phys. 203, 1602-1605 (2002).

Meltzer, T. H., and R. H. Supnik, "High speed tensile testing as an index of the oxidative degradation of polyethylene resins,” J. Appl. Polym. Sci. 8, 89-100 (1964).

Münstedt, H., "Dependence of the elongational behaviour of polystyrene melts on molecular weight and molecular weight distribution,” J. Rheol. 24(6), 847-867 (1980).

Münstedt, H., "Rheological properties and molecular structure of polymer melts," Soft Matter 7, 2273-2283 (2011).

Olley, P., and M. H. Wagner, "A modification of the convective constraint release mechanism in the molecular stress function model giving enhanced vortex growth," J. Non-Newtonian Fluid Mech. 135, 68-81 (2006).

Pages, P., F. Carrasco, J. Saurina, and X. Colom, "FTIR and DSC study of HDPE structural changes and mechanical properties variation when exposed to weathering aging during Canadian winter," J. Appl. Polym. Sci. 60, 153-159 (1996).

Peterson, J. D., S. Vyazovkin, and C. A. Wight, "Kinetics of the thermal and thermo-oxidative degradation of polystyrene, polyethylene and poly(propylene)," Macromol. Chem. Phys. 202, 775-784 (2001).

Rasmussen, H. K., and A. Bach, "On the bursting of linear polymer melts in inflation processes," Rheol. Acta 44, 435-445 (2005).

Rasmussen, H. K., J. K. Nielsen, A. Bach, and O. Hassager, "Viscosity overshoot in the start-up of uniaxial elongation of low density polyethylene melts," J. Rheol. 49(2), 369-381 (2005).

Rasmussen, H. K., and K. Yu, "On the burst of branched polymer melts during inflation,” Rheol. Acta 47, 149157 (2008).

Rasmussen, H. K., and T. Eriksson, "Gas displacement of polymer melts in a cylinder: Experiments and viscoelastic simulations,” J. Non-Newtonian Fluid Mech. 143, 1-9 (2007).

Resch, J. A., "Elastic and viscous properties of polyolefin melts with different molecular structures investigated in shear and elongation,” Ph.D. dissertation, Universität Erlangen-Nürnberg, Erlangen, 2010.

Rolón-Garrido, V. H., and M. H. Wagner, "The MSF model: Relation of nonlinear parameters to molecular structure of long-chain branched polymer melts," Rheol. Acta 46, 583-593 (2007).

Rolón-Garrido, V. H., and M. H. Wagner, "The damping function in rheology," Rheol. Acta 48, 245-284 (2009).

Rolón-Garrido, V. H., J. Luo, and M. H. Wagner, "Enhancement of strain-hardening by thermo-oxidative degradation of low-density polyethylene," Rheol. Acta 50, 519-535 (2011a).

Rolón-Garrido, V. H., J. A. Resch, F. Wolff, J. Kaschta, and H. Münstedt, "Prediction of steady-state viscous and elastic properties of polyolefin melts in shear and elongation," Rheol. Acta 50, 645-653 (2011b).

Rolón-Garrido, V. H., M. H. Wagner, C. Luap, and T. Schweizer, "Modeling non-Gaussian extensibility effects in elongation of nearly monodisperse polystyrene melts," J. Rheol. 50(3), 327-340 (2006).

Rolón-Garrido, V. H., R. Pivokonsky, P. Filip, M. Zatloukal, and M. H. Wagner, "Modelling elongational and shear rheology of two LDPE melts," Rheol. Acta 48, 691-697 (2009).

Roy, P. K., M. Hakkarainen, I. K. Varma, and A. C. Albertsson, "Degradable polyethylene: fantasy or reality," Environ. Sci. Technol. 45(10), 4217-4227 (2011).

Rychly, J., L. Matisova-Rychla, K. Csomorova, I. Janigova, M. Schilling, and T. Learner, "Non-isothermal thermogravimetry, differential scanning calorimetry and chemiluminescence in degradation of polyethylene, polypropylene, polystyrene and poly(methyl methacrylate), Polym. Degrad. Stab. 96, 1573-1581 (2011). 
Salvalaggio, M., R. Bagatin, M. Fornaroli, S. Fanutti, S. Palmery, and E. Battistel, "Multi-component analysis of low-density polyethylene oxidative degradation,” Polym. Degrad. Stab. 91, 2775-2785 (2006).

Schnabel, W., Polymer Degradation (Hanser, Munich, Germany, 1981).

Sentmanat, M., "Miniature universal testing platform: From extensional melt rheology to solid-state deformation behaviour," Rheol. Acta 43, 657-669 (2004).

Shangguan, Y. G., C. H. Zhang, Y. L. Xie, R. F. Chen, L. Jin, and Q. Zheng, "Study on degradation and crosslinking of impact polypropylene copolymer by dynamic rheological measurement," Polymer 51, 500-506 (2010).

Tüdos, F., and M. Iring, "Polyolefine oxidation: Rates and products," Acta Polym. 39, 19-26 (1988).

van Krevelen, D. W., and K. te Nijenhuis, Properties of Polymers. Their Correlation With Chemical Structure; Their Numerical Estimation and Prediction From Additive Group Contributions (Elsevier, Amsterdam, 2009).

Volke-Sepúlveda, T., E. Favela-Torres, A. Manzur-Guzmán, M. Limón-González, and G. Trejo-Quintero, "Microbial degradation of thermo-oxidized low-density polyethylene," J. Appl. Polym. Sci. 73, 1435-1440 (1999).

Wagner, M. H., "Analysis of time-dependent non-linear stress-growth data for shear and elongational flow of a low-density branched polyethylene melt," Rheol. Acta 15, 136-142 (1976).

Wagner, M. H., "A constitutive analysis of uniaxial elongational flow data of a low-density polyethylene melt," J. Non-Newtonian Fluid Mech. 4, 39-55 (1978).

Wagner, M. H., "The effect of dynamic tube dilation on chain stretch in nonlinear polymer melt rheology," J. Non-Newtonian Fluid Mech. 166(16), 915-924 (2011).

Wagner, M. H., J. Hepperle, and H. Münstedt, "Relating rheology and molecular structure of model branched polystyrene melts by molecular stress function theory," J. Rheol. 48(3), 489-503 (2004).

Wagner, M. H., M. Yamaguchi, and M. Takahashi, "Quantitative assessment of strain hardening of low-density polyethylene melts by the molecular stress function model,” J. Rheol. 47(3), 779-793 (2003).

Wagner, M. H., P. Rubio, and H. Bastian, "The molecular stress function model for polydisperse polymer melts with dissipative convective constraint release,” J. Rheol. 45(6), 1387-1412 (2001).

Wagner, M. H., and V. H. Rolón-Garrido, "Verification of branch point withdrawal in elongational flow of pom-pom polystyrene melt,” J. Rheol. 52(5), 1049-1068 (2008).

Wagner, M. H., and V. H. Rolón-Garrido, “The interchain pressure effect in shear rheology,” Rheol. Acta 49, 459-471 (2010).

Wagner, M. H., V. H. Rolón-Garrido, K. Hyun, and M. Wilhelm, "Analysis of medium amplitude oscillatory shear (MAOS) data of entangled linear and comb model systems,” J. Rheol. 55(3), 495-516 (2011). 
Copyright of Journal of Rheology is the property of Society of Rheology and its content may not be copied or emailed to multiple sites or posted to a listserv without the copyright holder's express written permission.

However, users may print, download, or email articles for individual use. 